\title{
Time-lapse resistivity analysis of Quaternary sediments in the Midlands of Ireland
}

\author{
Xavier M. Pellicer ${ }^{a}{ }^{\text {* }}$, Mario Zarroca ${ }^{b}$, Paul Gibson ${ }^{c}$ \\ a Geological Survey of Ireland, Beggars Bush, Haddington Road, Dublin 4, Ireland \\ b Departament de Geologia, Facultat de Ciencies, Universitat Autonoma de Barcelona, Spain \\ c Environmental Geophysics Unit, Department of Geography, National University of Ireland, Maynooth, Co. Kildare, Ireland
}

\section{A R T I C L E I N F O}

Article history:

Received 8 September 2011

Accepted 27 February 2012

Available online 6 March 2012

\section{Keywords:}

Electrical Resistivity Tomography (ERT)

Time-lapse

Quaternary sediments

Effective recharge

Temperature correction

Ireland

\begin{abstract}
A B S T R A C T
Electrical Resistivity Tomography (ERT) data are influenced by a number of factors associated with the subsurface such as porosity, moisture content and lithology; as well as external factors such as rainfall and temperature. Two time-lapse ERT profiles with $5 \mathrm{~m}$ and two with $2 \mathrm{~m}$ electrode spacings were acquired over a range of Quaternary sediment types encompassing till, esker gravel, glaciofluvial sand and silt and glaciolacustrine silt/clay. Data were collected on a monthly basis during 2006 at a site located in the Midlands of Ireland in order to evaluate the influence of such conditioning factors on the resistivity of the subsurface. Effective recharge, the depth of investigation, the texture and the internal architecture of the different sediment types and temperature variation are the main factors influencing the resistivity seasonal variation. The shallow subsurface ( $<3 \mathrm{~m}$ depth) showed a direct relationship between resistivity variation and effective recharge, whereas, an increasing time-lag between effective recharge and resistivity was recorded at increasing depths. As a result of the time-lag, it was possible to determine the rate of movement of the wetting/drying front for the unconsolidated relatively sorted coarse sediments recorded on the site at $7.8 \mathrm{~cm} /$ day. Conversely, poorly sorted and fine sediments show little resistivity variation and the velocity of the wetting front could not be estimated. Other factors influencing the electrical response of the subsurface are the electrode spacing used for data collection and the seasonal temperature variation of the subsurface. Two methods for temperature correction of electrical resistivity data were tested in this study - both gave similar results. Resistivity values recorded in the shallow subsurface $(<5 \mathrm{~m})$ show variations of over $15 \%$ subsequent to temperature correction. The results illustrate that seasonal temperature changes and their influence on subsurface temperature have to be accounted for in data interpretation and emphasise the potential of this technique for the estimation of the rate of movement of the wetting/drying front in soft sediments.
\end{abstract}

(c) 2012 Published by Elsevier B.V.

\section{Introduction}

Time-lapse resistivity imaging allows changes in the nature of the subsurface through time to be monitored. The lithology and the internal architecture of a site located in the Irish Midlands were characterised using the geophysical techniques Electrical Resistivity Tomography (ERT) and Ground Penetrating Radar (GPR) in combination with geomorphological, lithostrastigraphic and geotechnical investigations (Pellicer and Gibson, 2011). However, electrical resistivity research shows that porosity, moisture contents and temperature of the subsurface strongly influence the resistivity of soft sediments (Bernstone et al., 2000; Chambers et al., 2009; Guerin et al., 2004; Harmon and Hajicek, 1992; Hayley et al., 2009). Bulk resistivity of the subsurface is dependent on its fluid electrical conductivity (EC), temperature, saturation, porosity, and cation exchange capacity (CEC) or clay content (Hayley et al., 2007; Revil et al., 1998). On this basis, a year long time-lapse ERT

\footnotetext{
* Corresponding author.

E-mail address: Xavier.Pellicer@gsi.ie (X.M. Pellicer).
}

experiment was carried out on the site to observe the seasonal resistivity variation for four ERT profiles. A range of glacial and postglacial sediments with differing lithological and sedimentological settings were investigated in order to recognise their response to the shifting weather conditions throughout the year.

Time-lapse ERT is a methodology which attempts to detect variations in the electrical properties of the subsurface with time introducing an additional dimension into the data collection. This technique can be carried out through short time periods (several days with readings taken every few hours) to evaluate the migration of contamination plumes (Radulescu et al., 2007), detection and monitoring of concentration of a conductive contaminant within aquifers (Cassiani et al., 2006; Chambers et al., 2004; Oldenborger et al., 2007), quantification of superficial water infiltration rates into the subsurface (Barker and Moore, 1998) and tracer test monitoring (Monego et al., 2010; Ward et al., 2010). Long term time-lapse resistivity surveys have been applied to monitor seasonal variations on seepage rates (Johansson and Dahlin, 1996; Sjödahl et al., 2008), monitoring salinity within aquifers in coastal areas (de Franco et al., 2009; Leroux and Dahlin, 2006; Ogilvy et al., 2009), safety assessment for storage of 
nuclear waste (Yaramanci, 2000), estimation of subsurface temperature variation (Morard et al., 2008), observing changes in liquid water saturation and temperature in frozen ground (Hauck, 2002) and monitoring permafrost active layer thickness variation (Kneisel, 2006). In the Irish context, the use of time-lapse resistivity is limited; Gibson $(2003,2005)$ used this technique for monitoring seasonal effects on limestone bedrock and the movement of contamination plumes in a landfill.

The results of a time-lapse ERT experiment carried out on a monthly basis from January 2006 to December 2007 are presented in this paper. The aims of this study are twofold: to assess the seasonal variation of the resistivity values for a range of Quaternary sediments and to evaluate the seasonal evolution on the resistivity of the surveyed sediments at different depths. Such an experiment should aid in the understanding of the response of unconsolidated sediments to electrical resistivity surveys under changing weather conditions.

\section{Study area}

The study area is located in the Irish Midlands, $9 \mathrm{~km}$ east-southeast of Tullamore (Fig. 1a). A broad range of subsurface sedimentological
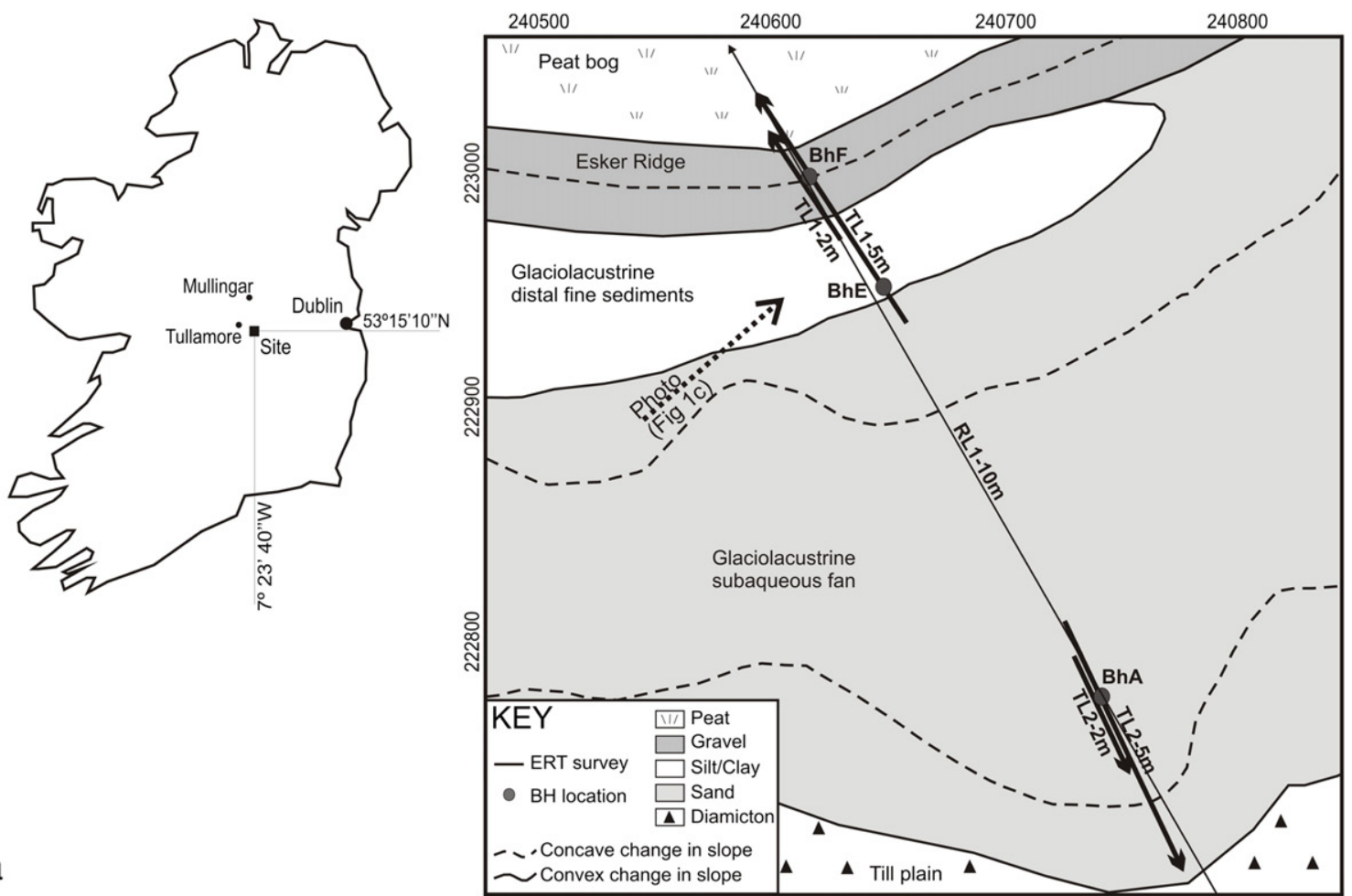

a

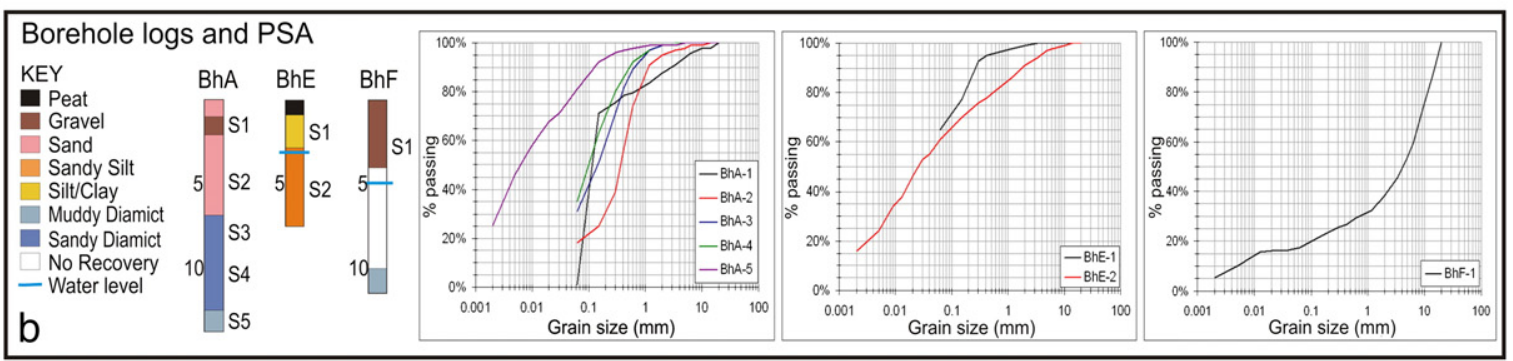

W

E

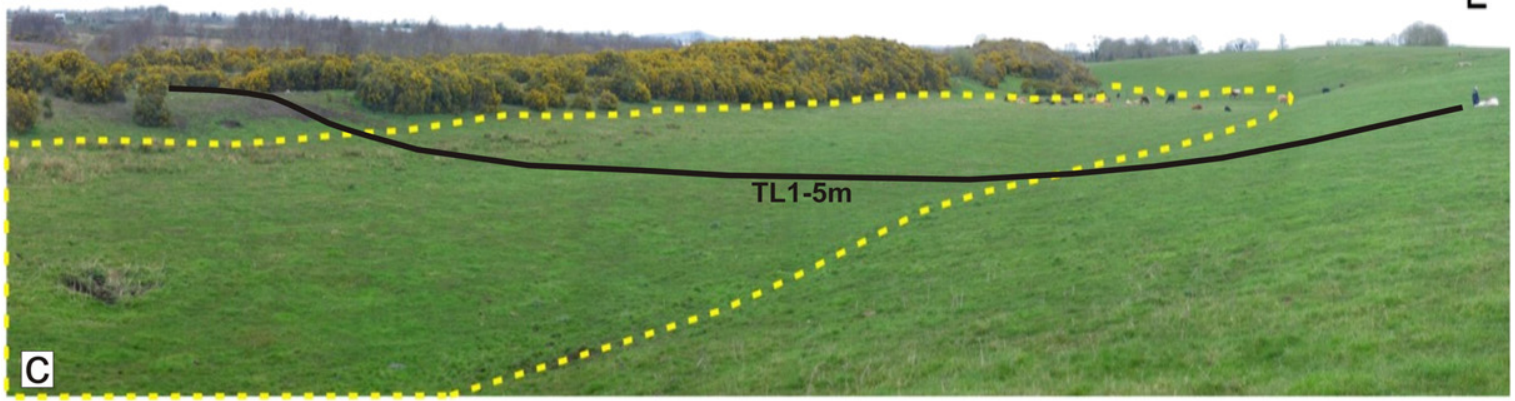

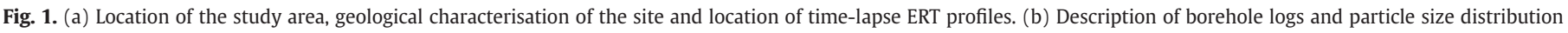

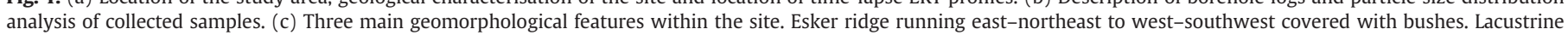
flat outlined with dashed line. Glaciolacustrine fan is located to its right. ERT profile TL1 - $5 \mathrm{~m}$ cuts across the three geomorphological features. 
and lithological characteristics are encountered in the site, which makes it suitable to assess the response of a range of unconsolidated sediments to time-lapse ERT analysis. A section of a topographically poorly-expressed esker ridge runs along the northern margin site in an east-northeast to west-southwest direction. It is dominated by poorly bedded muddy boulder gravel draped by a thin coating of diamicton, thickening towards the edges of the ridge and thinner on the ridge-top. The esker is bounded to the north by a low lying landscape dominated by peat underlain by lacustrine sediments and to the south by an east northeast-west southwest flat stretch of poorly-drained relatively low ground dominated by lacustrine silts and clays blanketed by a thin coating of peat (Fig. 1c). This lower ground is bounded to the south by a well drained, flat-topped, elongated glaciolacustrine subaqueous fan running east-west at $72 \mathrm{~m}$ above Ordnance Datum (OD), reaching a maximum height of $10 \mathrm{~m}$ above the surrounding landscape and encompassing widths of 200-450 m.

Three boreholes were drilled along the recorded ERT profiles (see location in Fig. 1a). BhA is located on the glaciolacustrine fan and is dominated by gravelly sand over gravelly muddy sand and overlying slightly gravelly sandy mud. BhE is located along the contact between the lacustrine flat and the fan and shows sandy mud overlain by a thin coating of peat and underlain by gravelly sandy silt; water head was recorded at $3 \mathrm{~m}$ depth. BhF was drilled on top of the esker; the top $4 \mathrm{~m}$ are dominated by muddy sandy gravel with silty sandy matrix, no recovery from 4 to $10 \mathrm{~m}$ and is composed of gravelly mud from 10-11.5 m; water head was recorded at $5 \mathrm{~m}$ depth. The water head was not encountered in BhA at $57.5 \mathrm{~m}$ OD. The borehole logs and the grain size distribution (BS EN ISO, 22476-2:2005, 2006) for each sample are presented in Fig. $1 \mathrm{~b}$. The available water-head records were collected during borehole drilling. The water table or a stable aquifer unit could not be established from these data alone. Water heads possibly correspond to disconnected flow paths associated with the coarse sediment units (esker gravel and glaciolacustrine gravelly sand) underlain by diamicton identified in BhA and $\mathrm{BhF}$ (Fig. 1).

\section{Methodology}

A Campus Geopulse resistivity metre with 25 electrodes was used to collect four time-lapse ERT profiles recorded on a monthly basis from January 2006 to January 2007 using the combined Wenner-Schlumberger array (WS). This array type was selected since both horizontal and vertical geological structures were expected. It is considered a good compromise between the Wenner array - enhancing its near-surface data coverage - and the dipole-dipole array - enhancing its signal-to-noise ratio - and provides a good balance between vertical and horizontal resolutions (Loke, 2011). Two main profiles, encompassing an electrode spacing of $5 \mathrm{~m}$, yielded information of a $120 \mathrm{~m}$ long profile reaching a maximum depth of $24 \mathrm{~m}$. Two other complementary profiles at $2 \mathrm{~m}$ electrode spacing were collected inline with the former, providing a $48 \mathrm{~m}$ long image of the subsurface and reaching a maximum depth of investigation of $9 \mathrm{~m}$. These datasets provided further high-resolution information of the electrical properties of selected sections of the $5 \mathrm{~m}$ spacing profiles. Contact resistances were measured before data collection and they were consistently below $2000 \Omega$ thus ensuring high data quality (Allied Associates Ltd., 2006). Salt water was applied to the electrodes where higher contact resistances were obtained. The highest contact resistances were measured in the drier months, however, they were generally below $1000 \Omega$. The parameter file for resistance data collection used by the Campus Geopulse system collected two readings for the $2 \mathrm{~m}$ spacing profiles and two/three readings for the $5 \mathrm{~m}$ spacing ones, the values obtained are averaged and the percentage error computed. The average percentage error for each profile together with the date of each survey and the air and soil temperatures during data collection are presented in Table 1. Error percentage variation is generally below $1 \%$, with the exception of data collected for line TL1 $-2 \mathrm{~m}$ from August to January 2007. Ideally, the
Table 1

Survey dates for the recorded time-lapse resistivity profiles including the temperature on the date of the survey, the ground conditions and the average\% error registered between the two/four readings collected for each data point.

\begin{tabular}{|c|c|c|c|c|c|c|c|}
\hline \multirow{2}{*}{$\begin{array}{l}\text { Survey } \\
\text { date }\end{array}$} & \multirow{2}{*}{$\begin{array}{l}\text { Air } \\
\text { temp } \\
\left({ }^{\circ} \mathrm{C}\right)\end{array}$} & \multirow{2}{*}{$\begin{array}{l}\text { Soil } \\
\text { temp } \\
\left({ }^{\circ} \mathrm{C}\right)\end{array}$} & \multirow[t]{2}{*}{ Ground } & \multicolumn{4}{|c|}{ Average\% error between readings } \\
\hline & & & & $\mathrm{TL} 1-5 \mathrm{~m}$ & $\mathrm{TL} 1-2 \mathrm{~m}$ & $\mathrm{TL} 2-5 \mathrm{~m}$ & $\mathrm{TL} 1-2 \mathrm{~m}$ \\
\hline $1 / 13 / 06$ & 9.3 & 7.4 & Moist & 0.14 & 0.57 & 0.31 & 0.04 \\
\hline $2 / 12 / 06$ & 8.5 & 6.8 & Moist & 0.16 & 0.52 & 0.04 & 0.55 \\
\hline $3 / 12 / 06$ & 7.7 & 6.8 & Moist & 0.18 & 0.65 & 0.04 & 0.31 \\
\hline $4 / 16 / 06$ & 10.9 & 10.7 & Dry & 0.15 & 0.88 & 0.06 & 0.27 \\
\hline $5 / 12 / 06$ & 13.6 & 16.5 & Dry & 0.96 & 0.20 & 0.44 & 0.11 \\
\hline 6/9/06 & 17.3 & 19.9 & Dry & 0.31 & 0.16 & 0.42 & 0.06 \\
\hline $7 / 15 / 06$ & 16.2 & 19.9 & Dry & 1.58 & 0.23 & 0.40 & 0.13 \\
\hline $8 / 14 / 06$ & 13.8 & 16 & Very dry & 1.54 & 0.52 & 0.31 & 0.06 \\
\hline 9/16/06 & 13.7 & 15.1 & Moist & 1.24 & 0.34 & 0.31 & 0.06 \\
\hline $\begin{array}{c}10 / 14 / \\
06\end{array}$ & 13.4 & 13 & Moist & 1.36 & 0.12 & 0.57 & 0.06 \\
\hline $11 / 9 / 06$ & 6.6 & 7.1 & Moist & 1.21 & 0.35 & 0.47 & 0.08 \\
\hline $\begin{array}{c}12 / 12 / \\
06\end{array}$ & 7.5 & 5.4 & Moist & 1.11 & 0.22 & 0.30 & 0.15 \\
\hline 1/19/07 & 8.8 & 6.4 & Moist & 1.10 & 0.20 & 0.10 & 0.16 \\
\hline
\end{tabular}

electrodes would have been installed permanently on site for the entire survey (Johansson and Dahlin, 1996; Yaramanci, 2000). However, due to logistical impediments, permanent electrodes could not be installed for such a long time period. Thus, the two ends of the profiles were marked by the installation of permanent wooden posts; measuring tape was used to relocate the electrodes in their original position for each profile during the length of the whole survey (14th January 2006-19th of January 2007).

The software package RES2DINV, which employs a least-squares optimisation approach to determine the true resistivity variation with depth, was used for the resistivity data inversion process (Loke and Barker, 1996). The software produces an inverse model of the measured apparent resistivity data. The apparent resistivity distribution that this model would produce is calculated (based on the array type and its sensitivity function). The Root Mean Square (RMS) error between the measured and the calculated apparent resistivity values is computed. The resistivity values of the cells are then iteratively altered to reduce the RMS error between the measured and the calculated data. Acceptable convergence was achieved after 5 iterations. From the time-lapse analysis perspective, the software package allows a joint inversion technique, where the inversion of the first measured resistivity data is used as a reference model to constrain the datasets collected at a later stage, this method has been used in previous research (Loke, 2001; Miller et al., 2008; Oldenborger et al., 2007). Miller et al. (2008) compared three methods for time-lapse data inversion and found that using a reference model for the inversion of additional datasets minimised the occurrence of noiserelated time-lapse artefacts. The final product from this process is a profile showing two of the datasets collected at different times, together with the percentage variation in resistivity.

Climatological data encompassing daily mean air temperature, mean soil temperature, rainfall and potential evapotranspiration were supplied by the Met Eireann Mullingar synoptic weather station, located $30 \mathrm{~km}$ north from the site. These data could not be collected in situ due to budget constraints. However, weather conditions in the region between Mullingar and the study site are very similar. The landscape in the region generally consists of low relief with an altitude difference between Mullingar and the site of less than $20 \mathrm{~m}$, moreover, rainfall and temperature data collected from Derrygreenagh weather station, situated $17 \mathrm{~km}$ northeast from the site show parallel results to the ones for Mullingar. The effective recharge for the area was determined using weather data from the Mullingar synoptic station. Effective recharge is the volume of rainfall water permeating into the subsurface below the root zone, thus 
influencing its geo-electrical response. Allen et al. (1998) presented a methodology to determine effective recharge for a range of soil types in Ireland based on the Penman-Monteith equation; the rainfall and potential evapotranspiration data obtained from the Mullingar synoptic station for a range of soil types and vegetation was used for this purpose. Effective recharge was determined from the rainfall and potential evapotranspiration data for a number of soils and vegetation types. Further details on the methodology are presented in Allen et al. (1998). This method was applied for the different sediment types encountered in the study area: sand, sandy loam, silty loam and silt/clay. Sandy loam was selected as the soil type to model the data on the basis that, (i) it is the dominant sediment type encountered along the four profiles, it is identified in samples BhA-2, BhA-3, BhA-4 and in BhF-1, (ii) effective recharge for the different lithologies is virtually the same, only the months of September and October show relatively higher values for sand and sandy loam, the differences in effective recharge encountered are of less than $6 \%$, which can be considered negligible for the resistivity variation of the subsurface. Furthermore, grass was selected as the vegetation type to estimate the effective recharge; grass overlies more than $95 \%$ of the ERT profiles and shrubs cover the remaining 5\%. The daily effective recharge for year 2006 for a sandy loam soil type with grass landcover is below $15 \mathrm{~mm}$ a day from January to May, it is null for the months of June, July, August and early September and increases significantly from October 2006 to January 2007 (Fig. 2a).

Seasonal variation of the subsoil temperature influences its resistivity. The magnitude of the apparent temperature effect was estimated by Hayley et al. (2007) at $\sim 2 \%$ change in resistivity per degree $C$, generally, temperature increase entails a decrease of the subsurface resistivity. Temperature variation with depth could not be measured in situ. However, yearly soil temperature at $15 \mathrm{~cm}$ depth recorded in the Mullingar synoptic weather station allowed estimating the depth temperature variation from the equation proposed by Musy and Soutter (1991) and modified by Brunet et al. (2010):

$T(z, t)=T_{\text {mean }}($ air $)+\frac{A_{0}}{2} e^{z / d} \times \sin \left(w t+\varphi_{0}-\frac{z}{4 d}\right)$

a

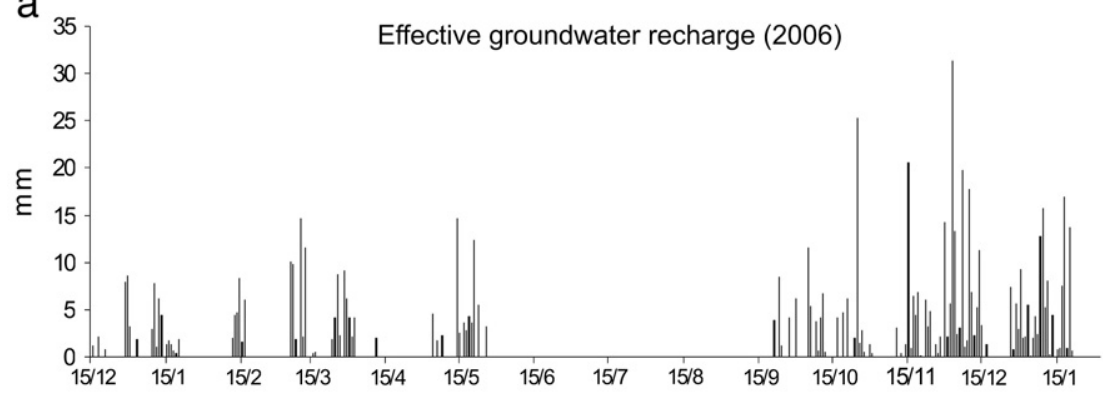

Theoretical temperature vs measured, $z=15 \mathrm{~cm}$

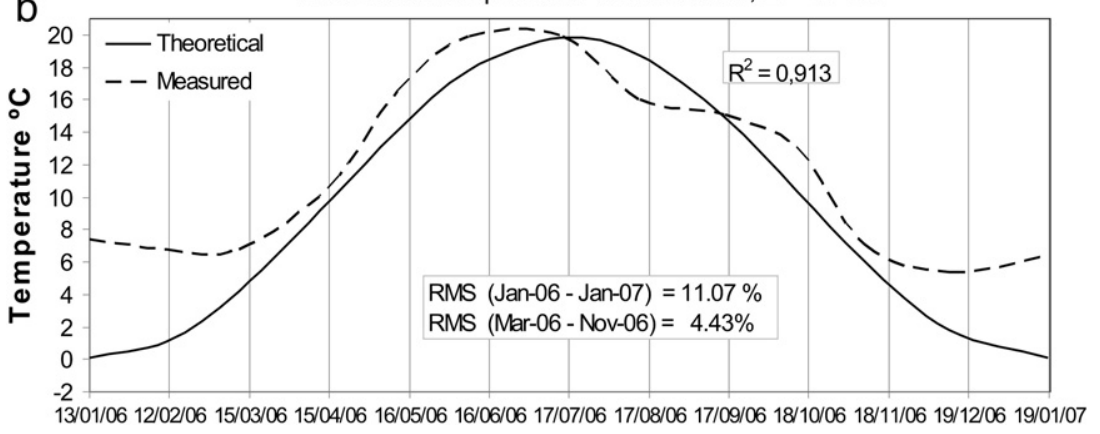

Fig. 2. (a) Effective recharge for year 2006 for sandy loam, data is estimated using the Penam-Monteith equation (Allen et al., 1998) from rainfall and potential evapotranspiration data from the Met Eireann Mullingar weather station. (b) Theoretical temperature curve adjusted to the measured temperature curve of the $15 \mathrm{~cm}$ depth provided by Met Eireann Mullingar weather station, curve shows a good correlation from March to November and poorer for the colder months. where $T(z, t)$ is the temperature of the subsoil at a given depth $(z)$; $T_{\text {mean }}($ air $)=9.96{ }^{\circ} \mathrm{C}$ is the yearly mean value of the air temperature; $A_{0}=22.7^{\circ} \mathrm{C}$ is the yearly temperature amplitude; $w=2 \pi / P$, where $\mathrm{P}=365$ days; $t$ is time since the time-lapse survey was started, $\varphi_{0}=-w \times t_{0}$ where $t_{0}=109$ days is the date the medium temperature is recorded and $d=1.1$ is the estimated depth parameter of the model. The parameter $d$ was computed by adjusting the theoretical curve of temperature to the measured data at $15 \mathrm{~cm}$ depth with a root square error of 0.913 , the theoretical curve shows a good adjustment from March to November with an RMS of $4.4 \%$ and weaker correlation for the winter months (Fig. 2b).

Two methods are proposed in the literature to remove the temperature effect from the time-lapse data (Hayley et al., 2007; Keller and Frischknecht, 1966). Both present a methodology to correct the measured electrical resistivity values to a standard temperature equivalent. A standard temperature of $10{ }^{\circ} \mathrm{C}$ was selected, as it corresponds to the average yearly temperature and the temperature of the subsoil at depths over $10 \mathrm{~m}$ (Goodman, et al., 2004), thus the magnitude of the temperature compensation is minimised. The equation proposed by Keller and Frischknecht (1966) was modified in order to standardise the resistivity at $10{ }^{\circ} \mathrm{C}$ :

$\rho 10=\rho T \times(1+\alpha(T-10))=\rho T \times K$

where $\rho 10$ is the resistivity value standardised $10{ }^{\circ} \mathrm{C} ; \rho T$ is the recorded resistivity value; $K=1+\alpha(T-10), T$ is the temperature at depth and $\alpha=0.025$ is an empirical coefficient illustrating a $2.5 \%$ variation of the electrical resistivity per $1{ }^{\circ} \mathrm{C}$. Brunet et al. (2010) experimentally tested this coefficient for temperatures between $6{ }^{\circ} \mathrm{C}$ and $26^{\circ} \mathrm{C}$ with satisfactory results. This was considered adequate for temperature correction, as this is the range of temperatures in the study area. The equation proposed by Hayley et al. (2007) for temperature correction of conductivity data, was modified by the authors to estimate the temperature correction of the measured resistivity data:

$\rho 10=\left[\frac{\mathrm{m}\left(T_{i}-25\right)}{\mathrm{m}\left(T_{S t d}-25\right)}\right] \rho_{i}=K \times \rho_{i}$ 
$K=\mathrm{m}\left(T_{i}-25\right) / \mathrm{m}\left(T_{\text {Std }}-25\right)$, where $\mathrm{m}=0.0183$ is the value of the slope of the linear model obtained from laboratory experiments for a range of glacial sediment samples at temperatures between 0 and $25^{\circ}$. (Hayley et al., 2007); $T_{i}$ is the temperature at a given depth; $T_{S t d}=10$; and $\rho_{i}$ is the recorded electrical resistivity.

The temperature correction using both methods was applied to all the profiles. The data presented in the article were corrected using the methodology by Hayley et al. (2007). The temperature correction effect on the measured resistivity is further discussed in Section 4.4 .

\section{Results and discussion}

\subsection{Data interpretation}

The time-lapse resistivity profiles were collected inline with the $10 \mathrm{~m}$ electrode spacing profile RL1 - $10 \mathrm{~m}$ (Fig. 1a), illustrating the distribution of the main stratigraphic units across the site (Fig. 3a). Water level recorded at $\mathrm{BhE}$ and $\mathrm{BhF}$ (Fig. 1) is estimated at $58 \mathrm{~m}$ OD. Medium to high resistivity values $(300-2000 \Omega \mathrm{m})$ dominate the glaciolacustrine subaqueous fan composed of either, sandy gravel or
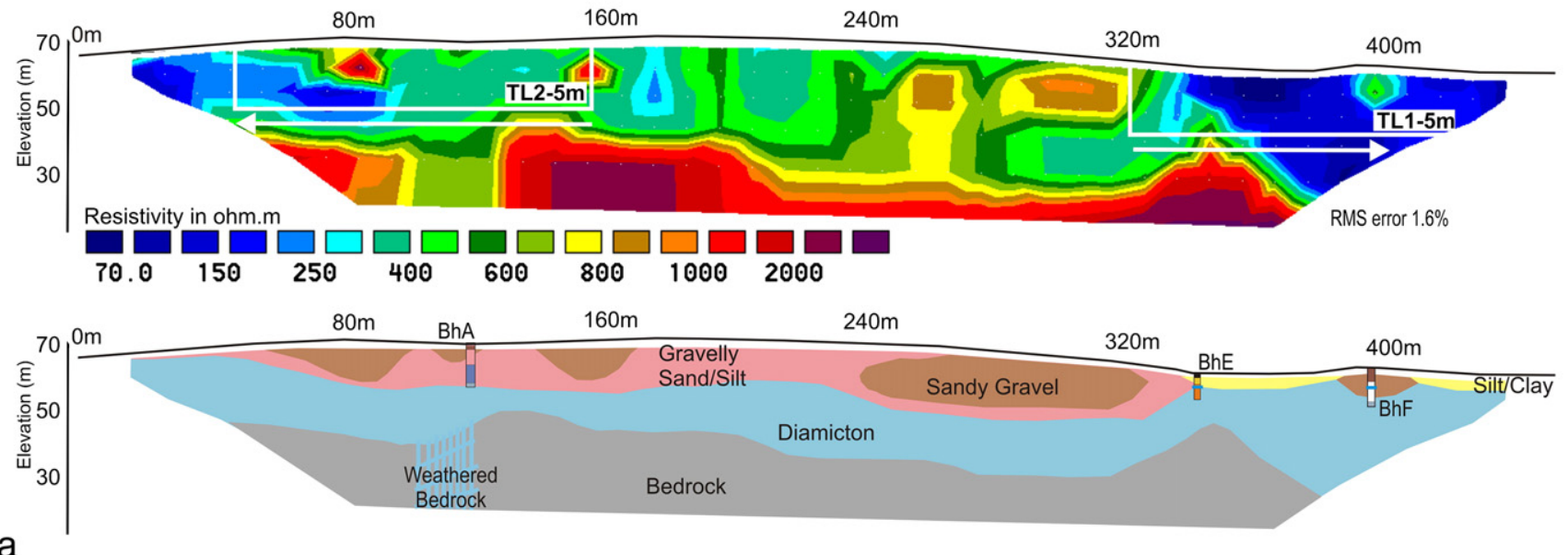

a
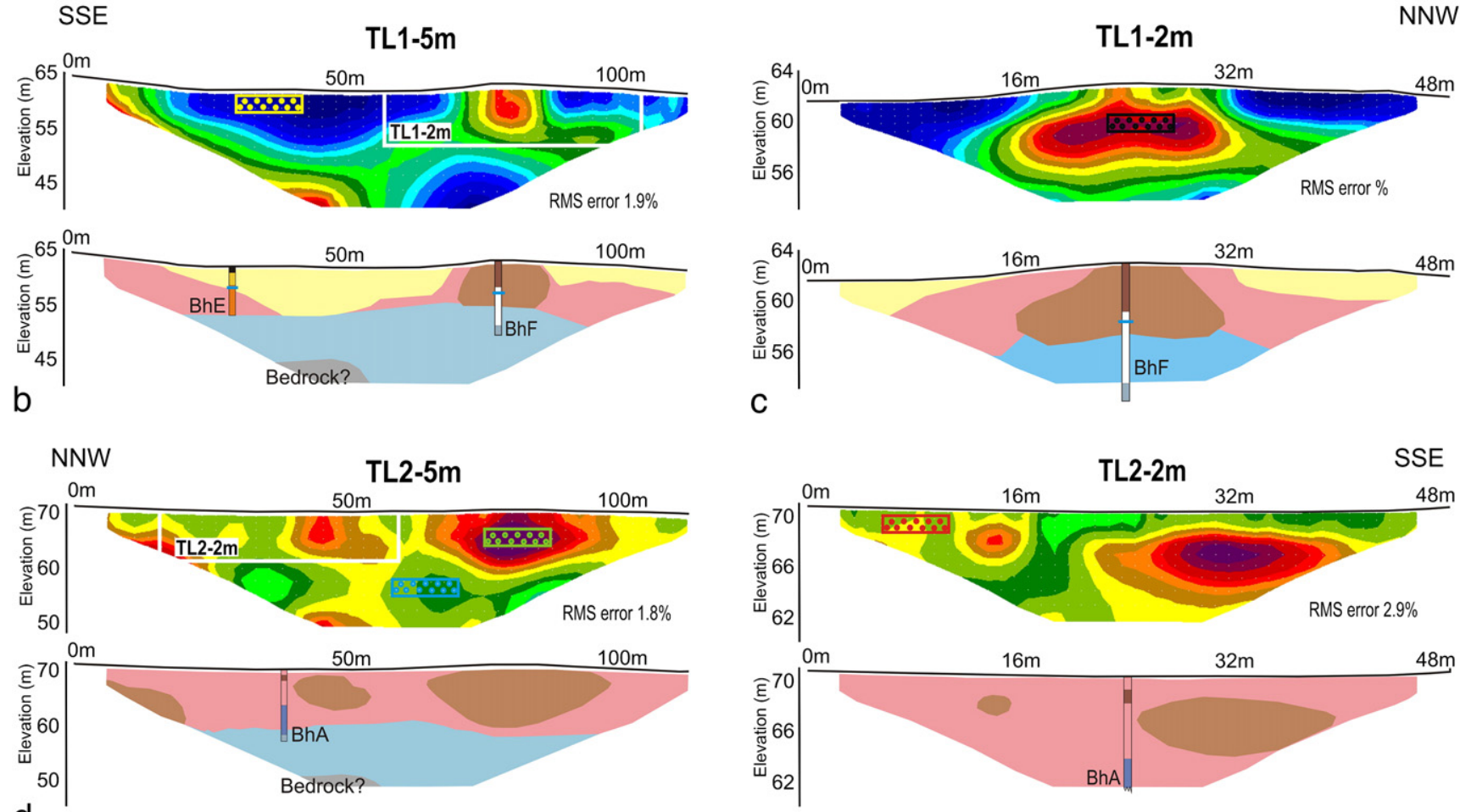

d

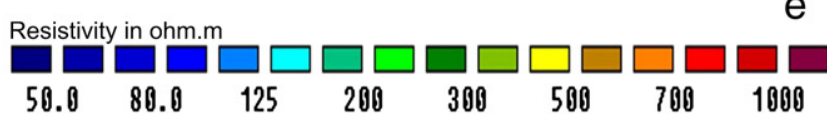

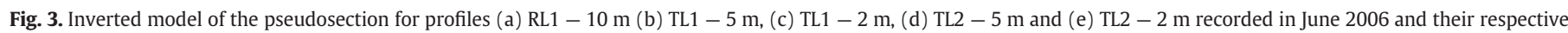
interpretation. Relative location of profiles is outlined in white, arrows indicate recording direction. 
gravelly mud. The section from x-position 330-390 m, representing glaciolacustrine distal sediments, is dominated by silts and clays characterised by low resistivity values $(<120 \Omega \mathrm{m})$ down to a depth of about $5 \mathrm{~m}$. The esker ridge composed of sand and gravel with resistivity of $400-800 \Omega \mathrm{m}$ is depicted from 390 to $410 \mathrm{~m}$. A layer underlying the former and outcropping to the surface at $0-50 \mathrm{~m}$ presents low to medium resistivity values $(100-500 \Omega \mathrm{m})$ and is interpreted as diamicton with a thickness varying from 5 to more than $25 \mathrm{~m}$. The lower part of the profile is dominated by high resistivity values ranging 1000-3000 $\Omega \mathrm{m}$ related to the bedrock basement underlying the diamicton with undulating topography. The resistivity profiles and their interpretation for the four datasets collected on the 9th of June of 2006 are presented below. TL1 - $5 \mathrm{~m}$ (Fig. 3b) shows a profile of the north margin of the subaqueous fan, the glaciolacustrine distal sediments and the esker. Two low resistivity zones $(<100 \Omega \mathrm{m})$ dominate the surface from 15 to $72 \mathrm{~m}$ and from 87 to $115 \mathrm{~m}$. These are interpreted as glaciolacustrine silt and clay overlain by a thin coating $(<0.30 \mathrm{~m})$ of peat (See BhE). The section from 72 to $86 \mathrm{~m}$ is dominated by $500-800 \Omega \mathrm{m}$ resistivity associated with cobble gravel with a muddy matrix reaching a thickness of 7-8 $\mathrm{m}$ and forming the core of the esker ridge running across the profile; the water level in BhF (Fig. 1b) is recorded at the lower section of this body. A zone, close to the surface from 0 to $20 \mathrm{~m}$ showing medium to high resistivity values (200-600 $\Omega \mathrm{m}$ ), is interpreted as gravelly sandy silt underlying fine sediments, the water level in BhE (Fig. 1b) is recorded at the interface of this layer with the overlying silts and clays. A low to medium resistivity area $(100-200 \Omega \mathrm{m})$ underlying all the sediments described above are interpreted as diamicton. Finally, a small area underlying the diamicton with values over $500 \Omega \mathrm{m}$ located at $38-57 \mathrm{~m}$, could correspond to the bedrock identified in RL1 - $10 \mathrm{~m}$ (Fig. 3a) or to an artefact produced during the inversion process in this low resolution/ sensitivity area. TL1 $-2 \mathrm{~m}$ (Fig. 3c) runs inline with TL1 $-5 \mathrm{~m}$ starting at its $58 \mathrm{~m} \mathrm{x}$-position. It illustrates a higher resolution crosssection of the esker ridge. The profile shows medium to high resistivity values $(>400 \Omega \mathrm{m})$ along the surface at $16-32 \mathrm{~m}$ and from 0 to $6 \mathrm{~m}$ depth, which is interpreted as cobble gravel with muddy matrix forming the core of the esker ridge (BhF). The top two metres, between $0-15 \mathrm{~m}$ and $33-48 \mathrm{~m}$, are dominated by very low resistivity values $(<60 \Omega \mathrm{m})$. These deposits are composed of lacustrine silt/clay. Moreover, low to medium resistivity values occurring in the area underlying the lacustrine sediments ranging from 60 to $400 \Omega \mathrm{m}$ are interpreted as gravelly muddy sand associated with the esker. A small patch of low to medium resistivity (100-300 $\Omega \mathrm{m})$ underlying the esker corresponds to the presence of diamicton. TL2 $-5 \mathrm{~m}$ (Fig. 3d) is entirely recorded on the glaciolacustrine subaqueous fan area. Resistivity values higher than $300 \Omega \mathrm{m}$ dominate the top $10 \mathrm{~m}$. Within this section, the areas with values higher than $500 \Omega \mathrm{m}$ are interpreted as deposits dominated by sand and gravel. It is inferred from their shape (see high resistivity areas $38-54 \mathrm{~m}$ and $65-100 \mathrm{~m}$ ) that these correspond to either, infill of buried channel features or lenses running across the profile. The areas dominated by lower resistivity values (300-500 $\Omega \mathrm{m}$ ) are interpreted as slightly gravelly muddy sand as recorded in BhA. Resistivity values lower than $300 \Omega \mathrm{m}$ dominate the lower parts of the profile and are interpreted as diamicton. Finally a small area displaying high resistivity located at the bottom of the profile at 42-56 m could correspond either to the bedrock recorded in RL1 $10 \mathrm{~m}$ or to an artefact produced during the inversion process in areas poorly constrained by the data. TL2 $-2 \mathrm{~m}$ (Fig. 3e) runs inline with $\mathrm{L} 2-5 \mathrm{~m}$ for $48 \mathrm{~m}$, starting at its $18 \mathrm{~m}$ point. It shows a higher resolution cross-section of the flat-topped area of the fan. The top metre is dominated by values of less than $300 \Omega \mathrm{m}$, interpreted as muddy sands. Two medium high resistivity areas $(>400 \Omega \mathrm{m})$ occur at $13-17 \mathrm{~m}$ and $22-40 \mathrm{~m}$. These are interpreted as sandy gravel bodies associated to either, the infill of buried channel features or lenses. Resistivity ranging from 150 to $400 \Omega \mathrm{m}$ dominate the remaining areas within the profile, these are interpreted as muddy sand; however, the resistivity values vary within short distances, indicating sudden variations in the proportion of sand and mud within these sediments.

\subsection{Analysis of seasonal data}

Seasonal resistivity variation of the subsurface mainly relates to the moisture content of the surveyed sediments, changes in fluid conductivity and to the varying temperature of the subsoil. The moisture content can be influenced by seasonal fluctuations of the water-table, by the volume of rainfall water permeating into the subsurface below the root zone (i.e. effective recharge) or both. Air temperature and the bedrock geology control the subsoil temperature.

Four profiles collected from January to October 2006, representative of each season for line TL1 $-5 \mathrm{~m}$, are presented in Fig. 4a. Visual analysis revealed a series of patterns. A significant increase in the resistivity during the drier months is detected in the esker and the glaciofluvial fan sand and gravel deposits and in a small area on the bottom left corner of the profile interpreted as bedrock, while, the regions dominated by finer sediments, sand and silt/clay, shows decrease of the resistivity values. The seasonal percentage difference (using the January 2006 profile as a baseline) is presented in Fig. 5a which reveals subtler changes of the geo-electrical response of different sediment types. The April profile shows a moderate increase in resistivity (10\%) in areas close to the surface, whereas regions at depths over $5 \mathrm{~m}$ underlying sand and gravel deposits exhibit a general decrease (10-20\%). The July dataset shows a substantial resistivity increase, larger for areas mapped as sand and gravel in shallow areas (>50\%), meanwhile the area below $5 \mathrm{~m}$ shows a general resistivity decrease $(20-40 \%)$. The shallow region of the October dataset shows resistivity increases in areas dominated by sand and gravel (10-40\%) and small decreases for regions underlain by silts and clays at $25-70 \mathrm{~m}$. Furthermore, the sediments overlain by silt/clay for the July and October datasets at 30-50 m experience a general increase in resistivity, whereas the 50-70 m region shows a drop in resistivity. Furthermore, large resistivity variations are observed in areas below the presumed water level, recorded in $\mathrm{BhE}$ and $\mathrm{BhF}$ (Fig. 2). Such variations are not feasible in a water saturated medium and two possible scenarios are contemplated: (i) the aquifer unit is perched and limited to disconnected coarse sediment units (gravel esker and glaciolacustrine gravelly sand) separated by lowpermeability fine-textured deposits (fine silts and clays) and underlain by diamicton (Fig. 3a); (ii) the observed resistivity variations are accentuated by noise of the data, by off-line 3D effects or by artefacts produced during the inversion process in poorly constrained areas of the model. A vertical feature observed in TL1 $-5 \mathrm{~m}$ at 30-50 m (Fig. 5a) showing an anomalous increase in the resistivity variation is interpreted as an artefact caused by the lower sensitivity of the deeper level inversion model-blocks. The Wenner-Schlumberger array generally produces an elongation of the boundaries of high resistivity isolated features enclosed in low resistivity bodies (Loke, 2011). These conditions, added to the larger size and the lower relative sensitivity of the deeper level model blocks, can produce such artefacts. However, despite the presence of artefacts, the resistivity variation pattern is analogous for both, TL1 $-5 \mathrm{~m}$ with a water head recorded at $5 \mathrm{~m}$ depth and TL2 $-5 \mathrm{~m}$ showing no evidence of groundwater flow. The recorded resistivity variations seem to respond mainly to the sediments' physical properties and, therefore, changes in the moisture content should play a key role in the seasonal resistivity variation for both profiles, TL1 $-5 \mathrm{~m}$ and TL2 $-5 \mathrm{~m}$.

Detailed seasonal profiles of esker gravel (line TL1 $-2 \mathrm{~m}$, Fig. 4b), show that drier months are associated with an increase in resistivity of the shallower areas of the esker ridge (top $1.5 \mathrm{~m}$ ) and a decrease of the deeper areas, indicating a movement towards the surface of high resistivity during the months with null effective recharge. The 
TL1-5m
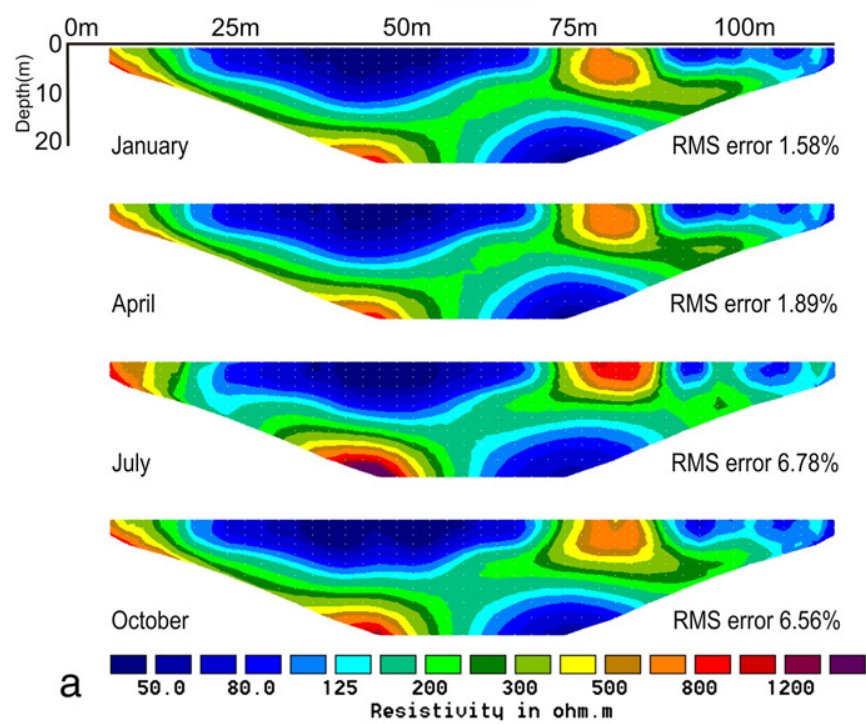

TL2-5m
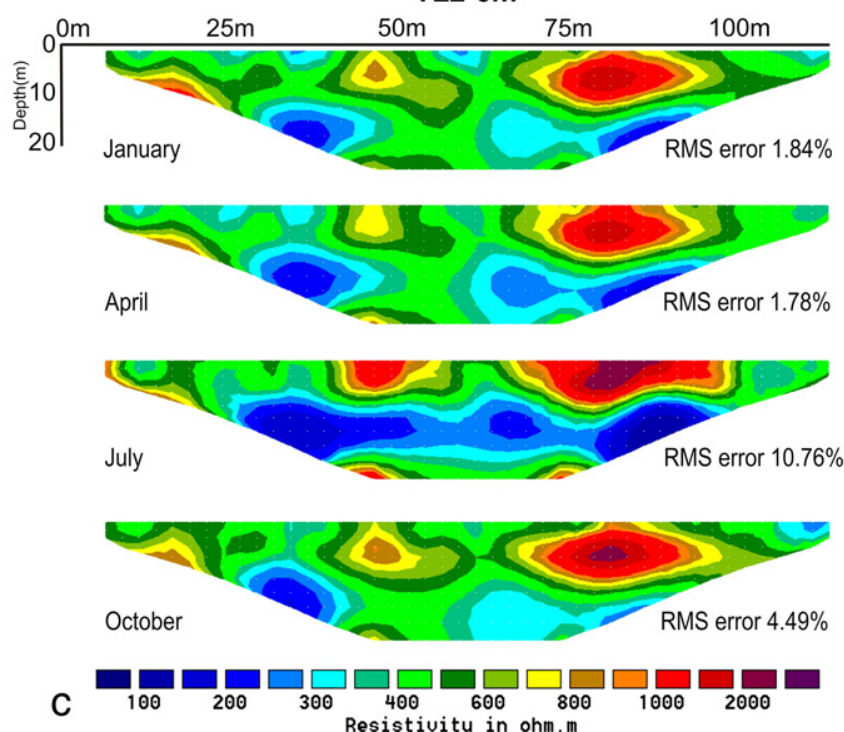

TL1-2m
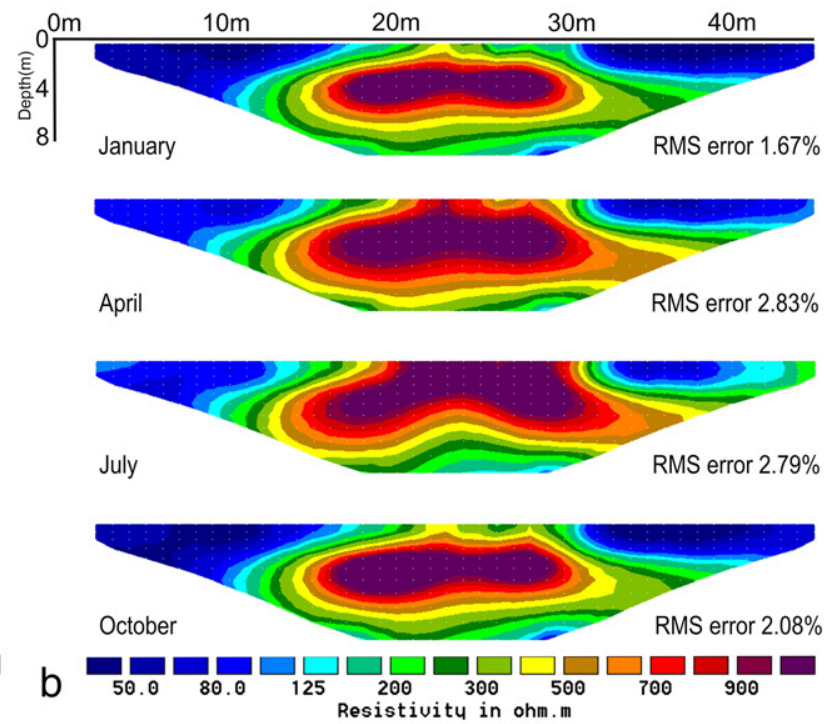

TL2-2m
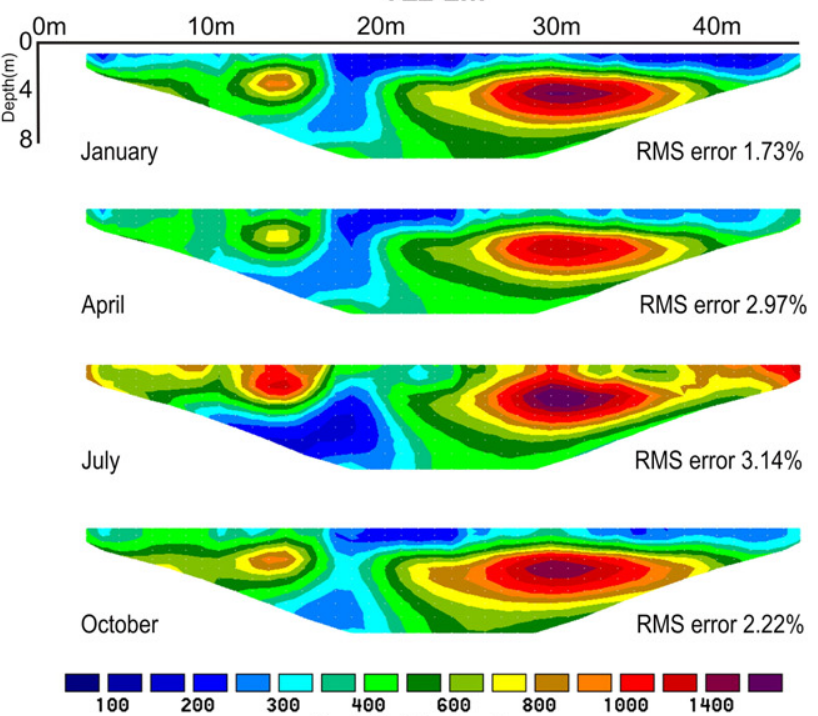

Fig. 4. Inverse model of the time-lapse ERT profiles (a) TL1 - $5 \mathrm{~m}$, (b) TL1 - $2 \mathrm{~m}$, (c) TL2 - $5 \mathrm{~m}$ and (d) TL2 - $2 \mathrm{~m}$ for each season.

regions surrounding the esker do not seem to experience major changes in their resistivity. Percentage variations for line TL1 $-2 \mathrm{~m}$ (Fig. 5b) display a similar pattern to TL1 $-5 \mathrm{~m}$. The April profile is illustrated by a moderate increase of the resistivity of the top $2 \mathrm{~m}$ (10-40\%), greater at the centre of the esker ridge and decreasing towards the edges. A moderate decrease is observed in the area below the esker ridge. The same pattern is observed in the July profile, however the resistivity variation reaches values of over the $100 \%$. Conversely, the October profile presents an increase in the resistivity at depths over $3 \mathrm{~m}$, whereas the areas overlain by mud located at the margins of the ridge experience a decrease in resistivity $(<20 \%)$. In the main, the largest resistivity increase concentrates along the upper $2-4 \mathrm{~m}$ of the central and the northern parts of the esker ridge, indicative of subtle differences in the composition of the sediments in these areas. On the other hand, the region below $4 \mathrm{~m}$ depth encompasses similar resistivity variations, probably representing relatively homogeneous lithological characteristics.

A changing pattern is observed in TL2 - $5 \mathrm{~m}$ (Fig. 4c). The inverse models for the wetter months (January, April and October) show a shallow area composed of medium resistivity (300-400 $\Omega \mathrm{m}$ ) enclosing two sand/gravel lens-like features at $45 \mathrm{~m}$ and $90 \mathrm{~m}$ underlain by a low to medium resistivity layer (100-500 $\Omega \mathrm{m})$. A third layer underlying the former showing medium to high resistivity (400-1000 $\Omega \mathrm{m}$ ) is depicted on the July profile, however, this could correspond to artefacts occurring in poorly constrained areas of the inverse model. Lens-like features observed close to the surface in the January, April and October datasets at 45 and $80 \mathrm{~m}$ are expressed as channel-like features in the July profile (Fig. 4c). Such changes in the shape of the depicted subsurface features could lead to the misinterpretation of the data, emphasising that knowledge of the climate driven subsurface temperature changes is essential for the correct interpretation of ERT data. Seasonal resistivity percentage variation for profile TL2 $-5 \mathrm{~m}$ (Fig. 5c) presents a similar pattern to profile TL1 $5 \mathrm{~m}$. The January vs. April profile encompasses a moderate increase of the resistivity of the top $2 \mathrm{~m}(10-20 \%)$ from 25 to $130 \mathrm{~m}$, and a general decrease of resistivity of the underlying materials, except for the bottom left corner area (Fig. 3d). The July profile shows a general resistivity increase of the top $5 \mathrm{~m}$. A dramatic increase of the resistivity in areas dominated by sandy gravel at $42-52 \mathrm{~m}$ and $70-90 \mathrm{~m}$ $(>50 \%)$ contrasts with a moderate increase of the areas composed 
TL1-5m - Seasonal \% Variation
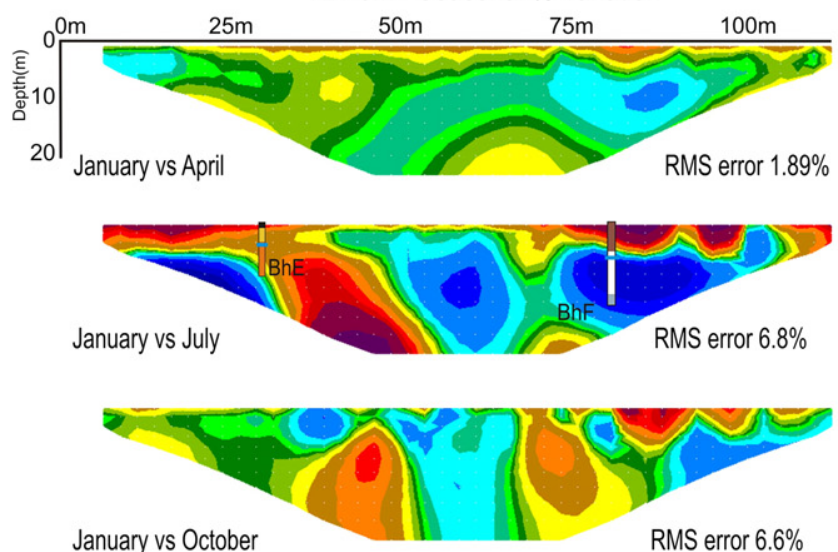

a
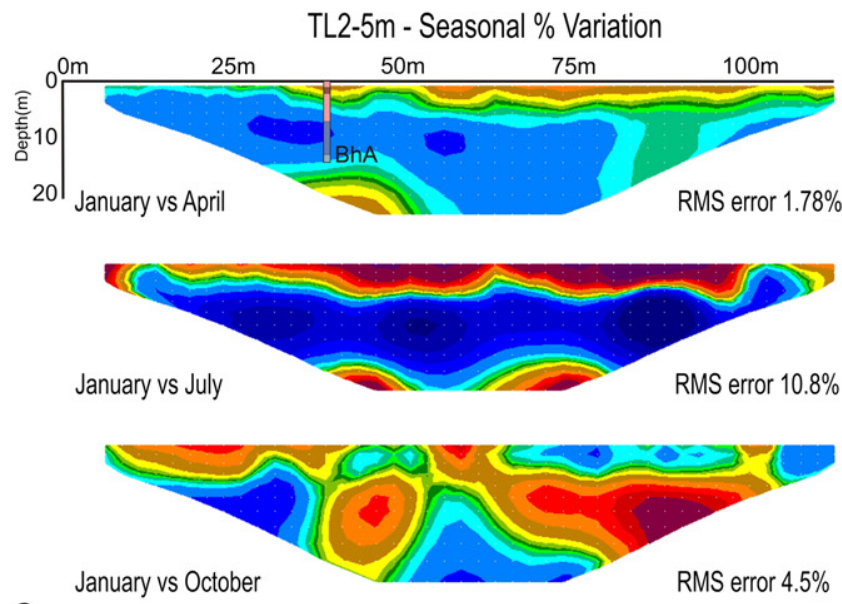

C
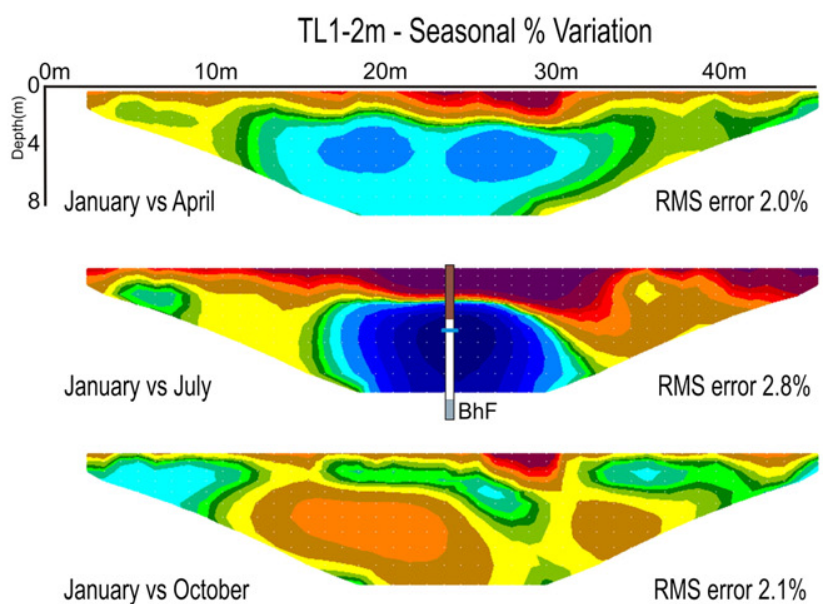

b
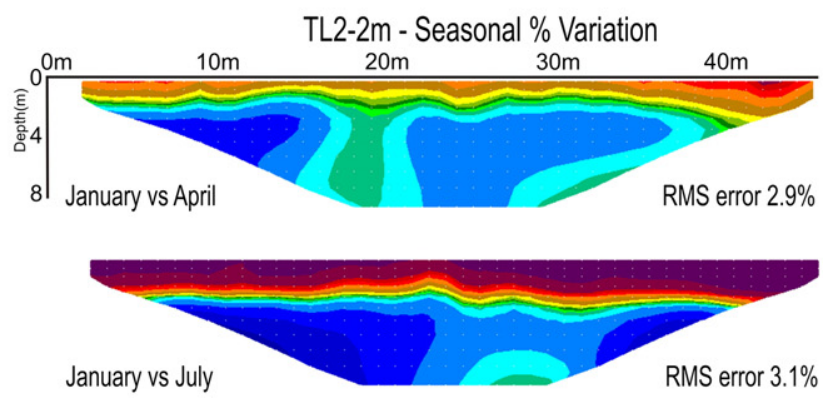

d

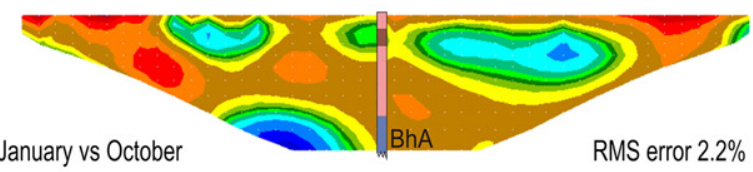

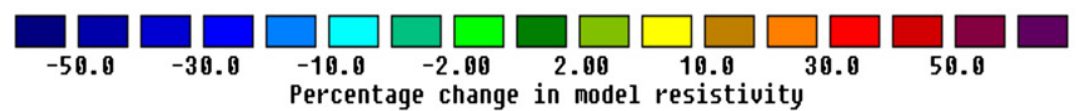

Fig. 5. Time-lapse ERT seasonal variation expressed in percentages for (a) TL1 - $5 \mathrm{~m}$, (b) TL1 - $2 \mathrm{~m}$, (c) TL2 - $5 \mathrm{~m}$ and (d) TL2 - $2 \mathrm{~m}$.

of muddy sand (10-30\%). Conversely, the areas at more than $5 \mathrm{~m}$ depth, overlain by sandy gravel show a large reduction of the resistivity ( $>50 \%$ ), whereas, a subtler reduction occurs in areas overlain by muddy sand. The opposite is observed on the shallow areas of the October profile. The resistivity values drop in the sandy gravel bodies (10-20\%), while areas composed of muddy sand increase their resistivity (10-40\%), confirming the different behaviour between fine and coarse sediments to the same external conditioning factors. This is probably caused by the different petrophysical characteristics of these materials, such as texture, porosity and permeability controlling the rate of movement of the wetting/drying front and causing the differences in resistivity of the sediments. On the other hand, a resistivity increase occurs for the areas underlying the sandy gravel bodies, indicating a decrease in moisture content of these sediments during October.

Following the same pattern observed above, TL2 $-2 \mathrm{~m}$ shows an increase of the high resistivity areas during July (Fig. 4d). Moreover, the section at 18-24 m, located in a small depression, encompasses low resistivity $(<300 \Omega \mathrm{m})$, which shows continuity in depth. This low resistivity vertical feature shows a similar pattern to depression-focused recharge areas encompassing higher volumes of water infiltration (Berthold et al., 2004; Hayashi et al., 2003) Visual analysis of percentage seasonal variation (Fig. 5d) points towards a significant increase in the resistivity values above $3 \mathrm{~m}$ depth during the drier season and a decrease of the resistivity values in the underlying areas. At this level of detail the percentage difference profile for April and July do not show obvious differences in relative resistivity variation between the areas dominated by gravelly sand from those dominated by muddy sand, both datasets show an increase (higher for the July profile $->50 \%$ ) of the resistivity in the shallow region and a decrease in the deeper parts. Conversely, the difference profile for January vs. October presents a subtle resistivity decrease of the sand and gravel bodies and an increase of muddy sand areas. A small lens recognised in this profile at $24 \mathrm{~m}$ and sampled in borehole BhA-1 (Fig. 1) that was not depicted in the inversion models of resistivity (Fig. 4d) is clearly detected in this profile.

\subsection{Analysis of monthly data}

In order to further understand the changes in resistivity throughout the year, the monthly resistivity values, for a number of sediment types occurring along the profiles and their associated effective recharge, are plotted as Cartesian diagrams. Two approaches to analyse the data are presented. Firstly, a number of points located at different depths, encompassing a range of lithologies, were selected aiming to recognise the influence of lithology, depth and effective recharge on the monthly resistivity variation (Figs. 6 and 7). Secondly, by plotting the data recorded at different depths for a given $\mathrm{x}$-location, the 
evolution of resistivity with depth compared to effective recharge could be determined (Fig. 8). The methodology established by Allen et al. (1998) allowed the determination of effective recharge for a range of materials. Particle size distribution analysis carried out in samples from the boreholes (BhA, BhE, BhF) allowed the dominant site lithological types to be characterised: sand, sandy loam, silt loam and silt/clay. The effective recharge for these sediments was determined and the values for sandy loam are presented in Fig. 2. The sum of the effective recharge for the 30 day period before data collection for each material is plotted in the Cartesian diagrams to analyse its correlation with resistivity data.
The location and lithological classification for the five points selected for TL1 $-5 \mathrm{~m}$ are illustrated in Fig. 6a. Resistivity for gravelly mud (R1) and muddy gravel (R3) shows a significant increase during the drier months when effective recharge has no effect, followed by a resistivity decrease from September 06 to January 07. Silt/clay (R2) and diamicton (R4 and R5) encompass small resistivity variations of less than $10 \%$ throughout the year. The monthly resistivity for the five data points selected for TL1 $-2 \mathrm{~m}$ is illustrated in Fig. 6b. Two points recorded at $1 \mathrm{~m}$ depth in silt/clay ( $\mathrm{R} 1$ and $\mathrm{R} 2$ ) show an increase in resistivity values during the summer ( $>15 \%)$, while, R3, also recorded at $1 \mathrm{~m}$ depth, but in muddy gravel, shows an increase
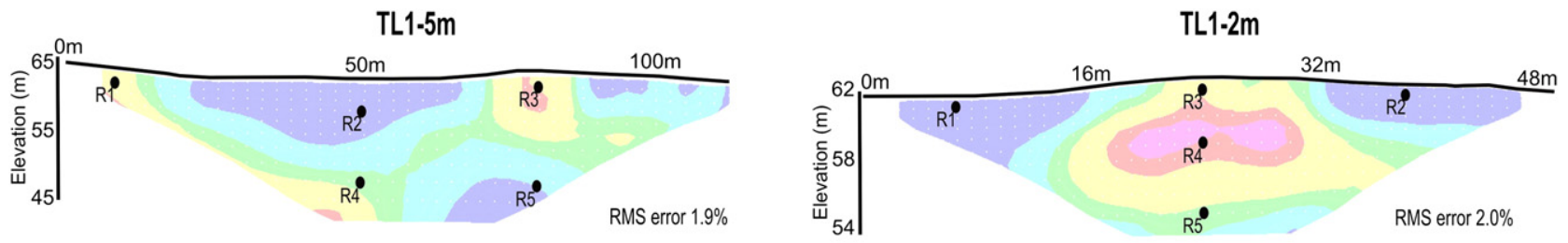

$50.0 \quad 80.0 \quad 125 \quad 200$
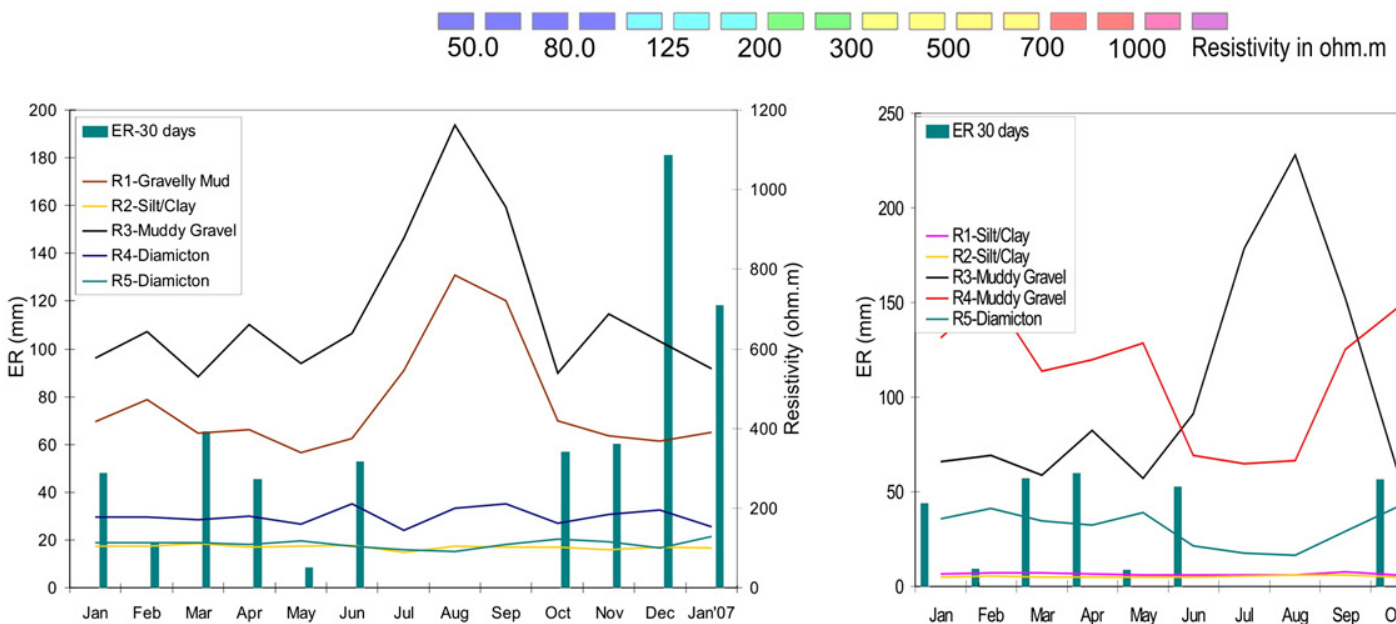

a

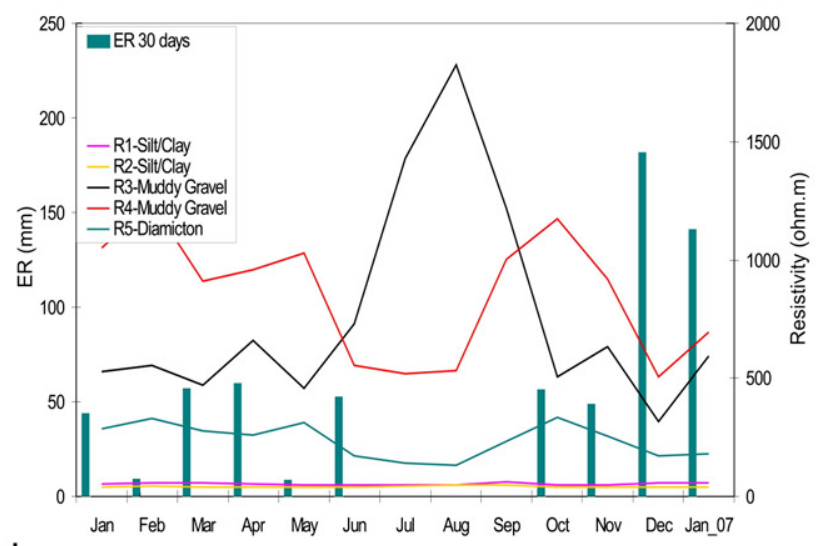

b
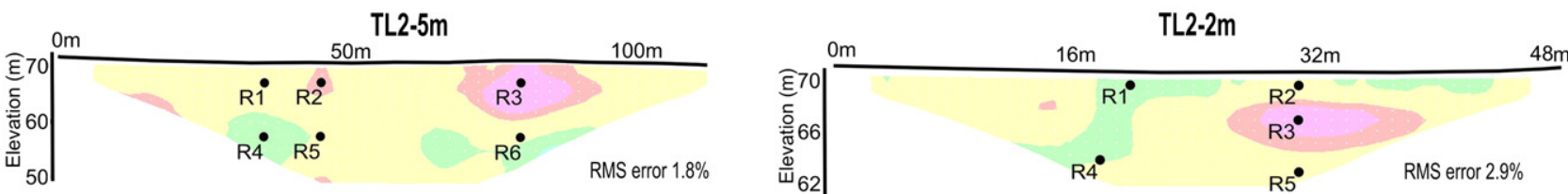

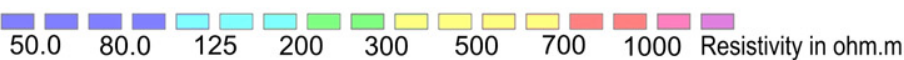
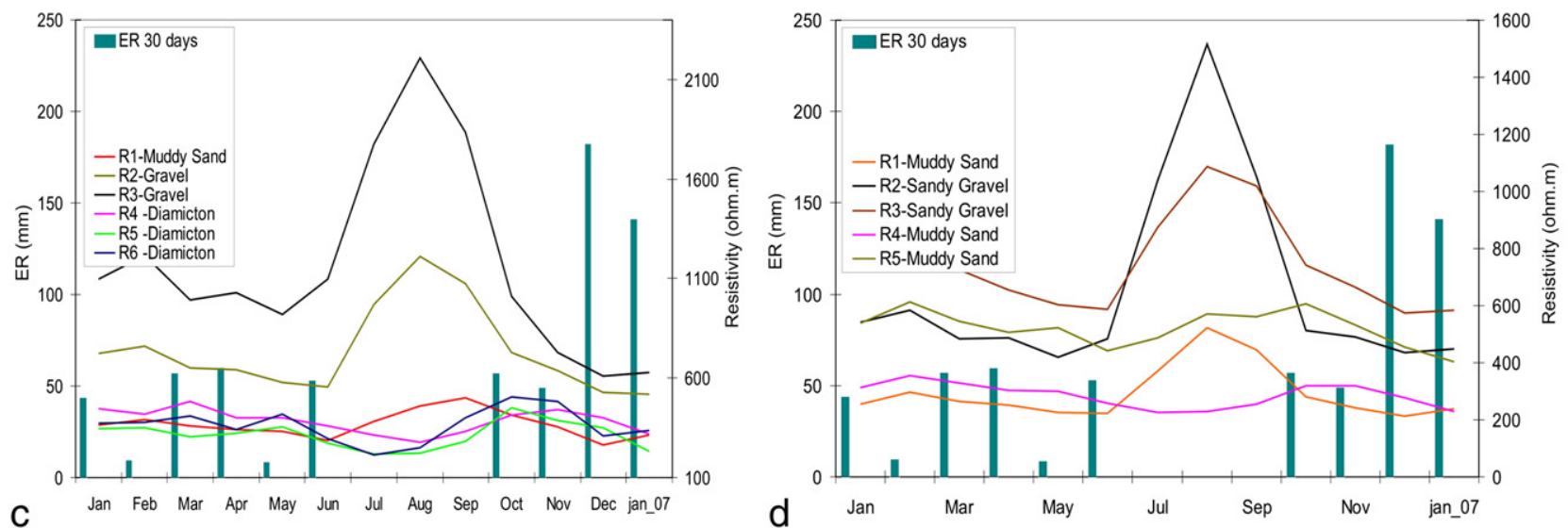

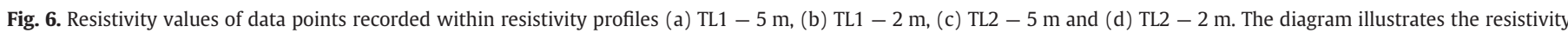
variation for a range of sediment types through year 2006 plotted against the 30 days cumulative effective recharge. 


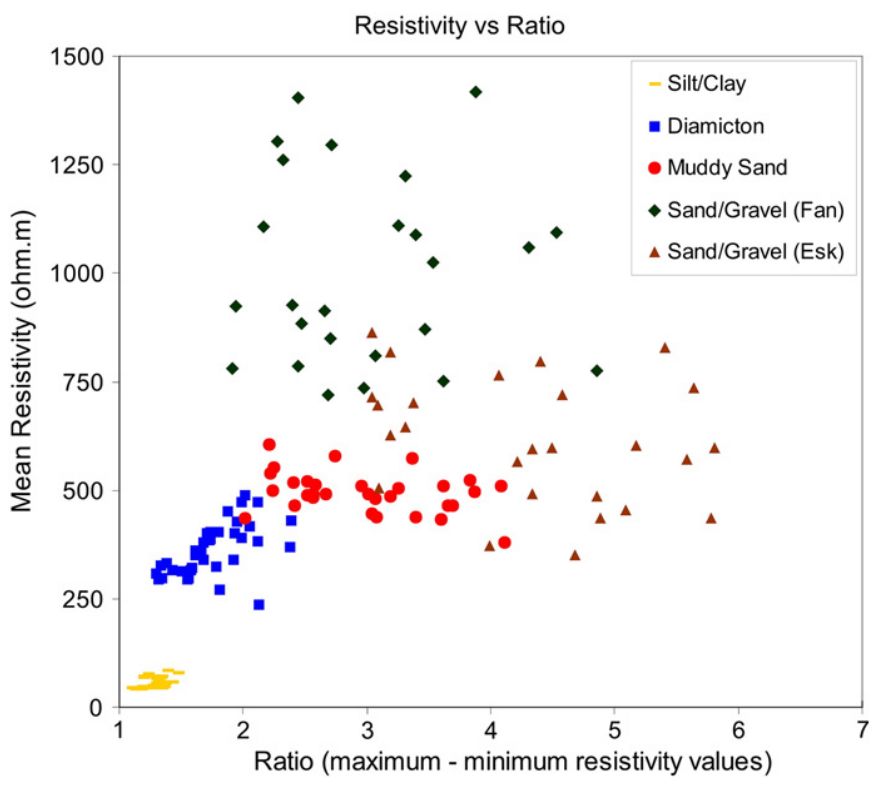

Fig. 7. Yearly resistivity variation for the materials recognised in the site. The resistivity values of the plotted points were extracted from the 5th iteration of the inverse model of the pseudosection. The location of the plotted points is shown as dotted rectangles in Fig. 3: silt/clay (yellow - TL1 $-5 \mathrm{~m}$ ); diamicton (blue $-\mathrm{TL} 2-5 \mathrm{~m}$ ); muddy sand (red TL2 $-2 \mathrm{~m}$ ); sand/gravel fan (green - TL2 $-5 \mathrm{~m}$ ) and sand/gravel esker (brown - TL1 $2 \mathrm{~m}$ ). X-axis displays the ratio of maximum and minimum resistivity values from January 2006 to January 2007, y-axis shows the mean yearly resistivity value for each point.

of over $100 \%$. The resistivity values recorded for points R4 and R5 that are located at 3.8 and $8 \mathrm{~m}$ depths respectively, drop during the drier season. The petrophysical characteristics of the sediments control significantly the behaviour related with resistivity seasonal variation. Coarse sediments are characterised by high hydraulic conductivity allowing significant variations in saturation degree related to the environmental conditions. However, fine textured sediments, with large specific surface area and poor hydraulic conductivity, show a subtler response to variations in moisture content (Fig. 7). The electrical conductivity of coarse sediments is controlled by the fluid conductivity, while surface conduction and retained salts on clay mineral grains contribute significantly to the conductivity of clay rich matrix sediments (Shevnin et al., 2006; Zarroca et al., 2011). Grain size decrease involves an increase of the surface conduction (Huntley, 1987). Therefore, increasing proportion of clay mineral in the sediments results in decreasing mean resistivity values and in subtler response to seasonal changes in moisture content (Fig. 7).

Six data points were selected for TL2 $-5 \mathrm{~m}$, their lithology and location within the profile are illustrated in Fig. 6c. Three points recorded at $4 \mathrm{~m}$ depth in muddy sand (R1) and gravelly sand (R2, R3) show an increase in their resistivity during the summer and relatively steady values during the rest of the year. This resistivity increase is smaller for the muddy sand (40\%) than for the gravelly sand (55\%). Three points recorded at $14 \mathrm{~m}$ depth show resistivity decrease during the summer months, R4 and R5 show a drop in the resistivity values from June to September and R6 from June to August. These resistivity decreases are followed by an important increase in resistivity from September to November, especially significant for point R6 (>100\%) and a subsequent drop from November to January 07. Data points analysed for TL2 $-2 \mathrm{~m}$, are illustrated in Fig. 6d. Points R2 and R3 recorded as sandy gravel at 1-4 m depths respectively show a resistivity increase from July to September ( $>100 \%$ for R2) and a little change for the remaining months. Point R5, dominated by muddy sand, underlying the former at $8 \mathrm{~m}$ depth shows a steady resistivity decrease from January to June, an increase from June to October and a steady decrease through autumn and winter.
$\mathrm{R} 1$, at $1 \mathrm{~m}$ depth, overlies R4 (7 m depth), both being muddy sand. The expected increase in resistivity values during the drier months is observed for $\mathrm{R} 1$ (>100\%), whereas, $\mathrm{R} 4$ shows a 30\% drop in resistivity values from June to September, an increase from September to November (>30\%) and a drop for December and January 07 (>30\%).

The analysis of time-lapse resistivity data has revealed a number of patterns. Shallow areas within the profiles appear to respond very rapidly to changes in effective recharge and an increase in the resistivity of $20-100 \%$ generally occurs in the top $2-4 \mathrm{~m}$ during the months of July, August and September (with zero effective recharge). This is more evident for coarse sediments than for silt/clay. On the other hand, the deeper areas generally show a decrease of the resistivity values during the drier season $(>50 \%)$ followed by an increase ( $>100 \%$ in places) in resistivity immediately after it. The resistivity variation seems to be controlled in this instance by five attributes: the effective recharge, the depth, the texture of recorded sediments, the texture of the material overlying it and the subsurface temperature. However, resistivity variations depicted in areas under the water heads, recorded in boreholes $\mathrm{BhE}$ and $\mathrm{BhF}$, may be inconsistent with the resistivity variation expected in the saturated zone. Such changes are generally recorded at the bottom of the inverse model (e.g. R5-TL1 - $2 \mathrm{~m}$ in Fig. 6). As discussed before, the probable perched nature of the aquifer units and/or the presence of potential artefacts produced in the deeper levels during the inversion modelling process could answer for these inconsistencies.

Field mapping, geophysical characterisation of the study area (Pellicer and Gibson, 2011) and borehole data (Fig. 2) permitted the tentative categorisation of five lithological classes within the profiles (Fig. 3). The yearly mean resistivity and its variation (ratio of maximum and minimum resistivity values recorded through the year) for sediments are clearly influenced by their texture. Sediments with fine matrix (silt/clay) present low resistivity mean values and comprise minor resistivity variations. Sediments with muddy matrix such as diamicton and muddy sand encompass medium mean resistivity $(200-600 \Omega \mathrm{m})$ and ratios of $1.2-2.4$ and $2-4$, respectively. Coarse sediments (sand and gravel) comprise the highest mean resistivity values and fairly large ratios (Fig. 7).

Materials lying close to the surface react rapidly to changes in effective recharge as illustrated by the rapid increase of the resistivity values during the summer months. However, there is an increasing time lag with depth between the effective recharge and its influence on the resistivity values recorded. This time lag with depth is illustrated for the different sedimentological settings recognised along the ERT profiles (Fig. 8). TL1 $-5 \mathrm{~m}$ at $45 \mathrm{~m}$ shows fine glaciolacustrine sediments overlying diamicton (Fig. 8a). A minor resistivity variation (<20\%) occurs in the top $8 \mathrm{~m}$ and resistivity of diamicton varies by $20 \%$ in July and October. TL1 $-2 \mathrm{~m}$ at $25 \mathrm{~m}$ illustrates the resistivity variation of muddy gravel overlying diamicton (Fig. 8b), the shallower areas present steady values from January to May, a dramatic resistivity increase ( $>100 \%$ ) during the drier months with its peak in August and a sharp decrease in October (first survey with precipitation after three months) of the top $2 \mathrm{~m}$. Regions at more than $4 \mathrm{~m}$ depth show a gradual migration of this higher resistivity peak towards October and unexpected minimum resistivity values for the year during the drier months, moreover, resistivity of all records gradually decrease from October to December. Effective recharge is null till the 21st of September (Fig. 2a) and this is illustrated by a decrease in resistivity for the October survey at depths less than $300 \mathrm{~cm}$. However, points at depths over $380 \mathrm{~cm}$ show a time lag of 49 days (9th of November survey) to its resistivity reduction (Fig. 8b). This time lag observed between the increase of effective recharge and resistivity decrease allows an estimation of the velocity of the wetting front at $380 \mathrm{~cm} / 49$ days $=7.8 \mathrm{~cm} /$ day. Muddy sand with gravelly sandy lenses overlying diamicton are recorded in TL2 - $5 \mathrm{~m}$ at $57.5 \mathrm{~m}$ (Fig. 8c). Resistivity and effective recharge show a direct relationship in the top $6 \mathrm{~m}$, however, the response of resistivity to effective recharge gradually lessens towards deeper areas dominated by 

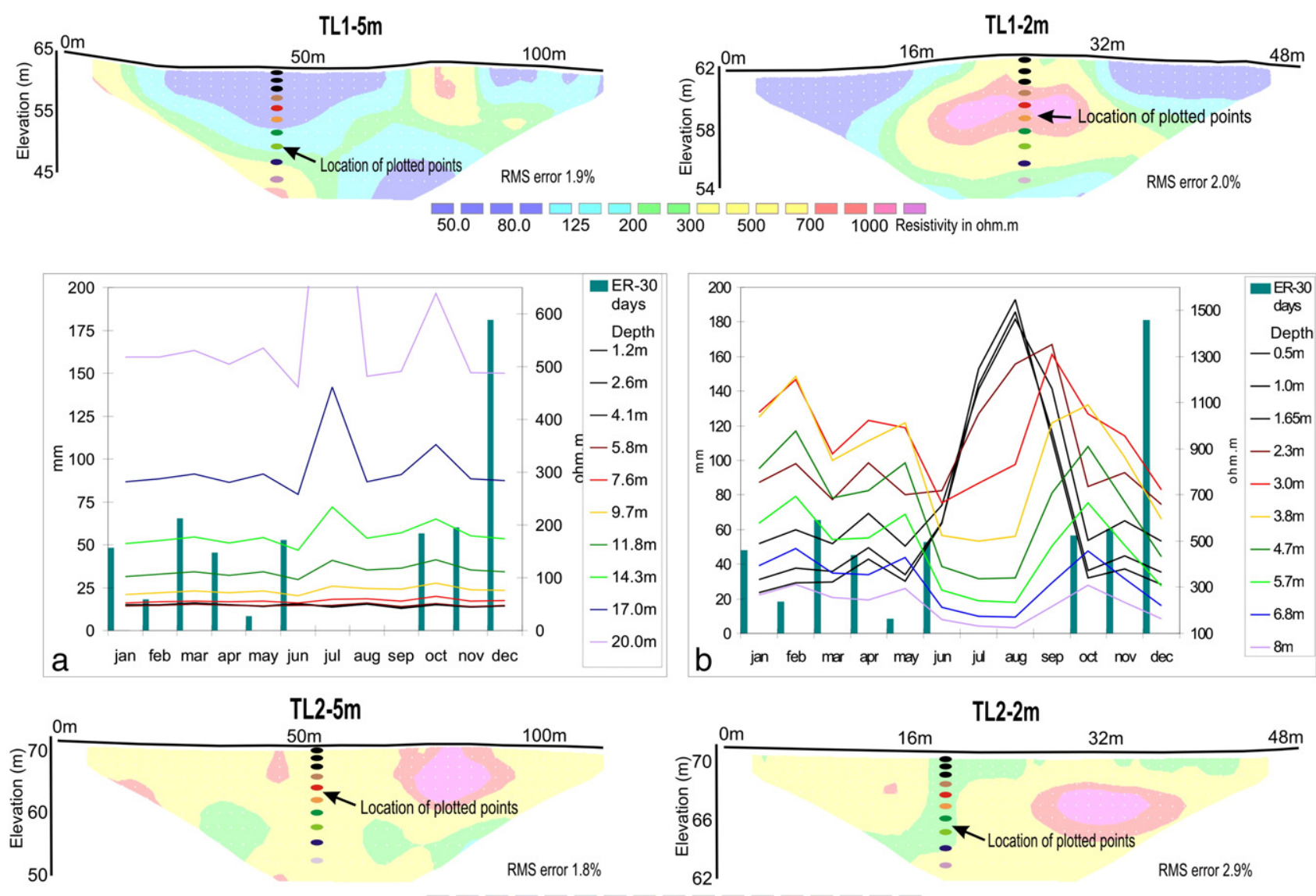

$\begin{array}{lllllll}50.0 & 80.0 & 125 & 200 & 300 & \square 00 \quad 700 & 1000 \text { Resistivity in ohm.m }\end{array}$
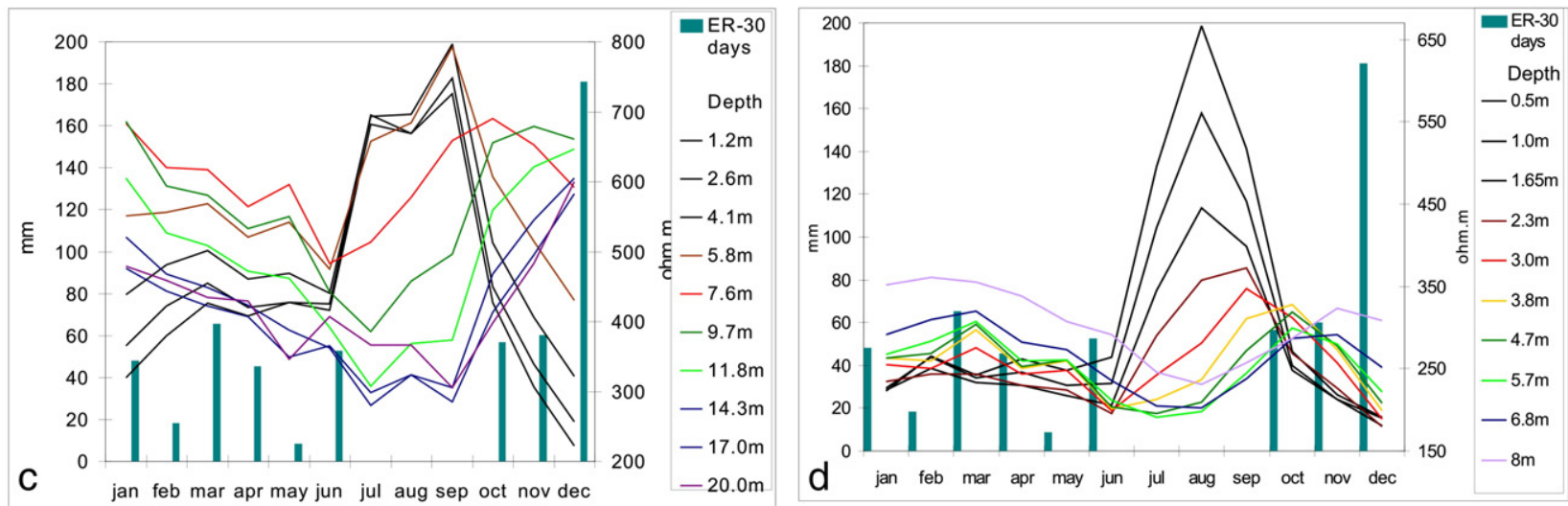

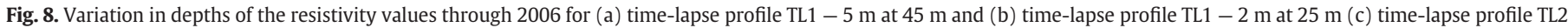
$-5 \mathrm{~m}$ at $57.5 \mathrm{~m}$ and (d) time-lapse profile RTS1-L02 $-2 \mathrm{~m}$ at $19 \mathrm{~m}$. Temperature correction is applied to profiles (b) and (d).

diamicton. Points recorded at $7.6 \mathrm{~m}$ and $9.6 \mathrm{~m}$ depths react in November and December to the increasing effective recharge recorded in October and the area at depths over $970 \mathrm{~cm}$ dominated by diamicton with silty clayey matrix shows a delay of 83 days in the resistivity decrease associated with the effective recharge starting in September; Velocity of the wetting front is estimated at $970 \mathrm{~cm} / 83$ days $=11.7 \mathrm{~cm} /$ day from these figures. Resistivity recorded for profile TL2 $-2 \mathrm{~m}$ at point $19 \mathrm{~m}$ for 10 different depths (Fig. 8d) for the same period of time shows a similar pattern to the former, however in this instance the spatial resolution is higher and a month time lag in resistivity response to dry weather is recorded at a shallower depth $(3.8 \mathrm{~m})$. Seepage of water through the subsurface results in a time lag of at most 49 days for sediments at depths over $380 \mathrm{~cm}$, the velocity of the wetting front is estimated at $380 \mathrm{~cm} / 49$ days $=7.8 \mathrm{~cm} /$ day. The estimated seepage velocity depends on the time and spatial resolutions of the datasets. The spatial resolution of the $5 \mathrm{~m}$ spacing dataset is probably too coarse to estimate seepage velocity. Furthermore, the decreasing spatial resolution of ERT profiles with depth reduces even more the accuracy of these estimates. The velocities presented can only be considered as approximate figures. Nevertheless, the estimated seepage velocity values fall within the category of semi-pervious aquifers composed of gravel, sand, silt and loam (Bear, 1972), which agrees with the particle size analysis results of the collected samples (Fig. 1b).

\subsection{Electrical resistivity temperature correction}

Temperature corrections, as illustrated by the $\mathrm{K}$ values obtained from Eqs. (2) and (3), were applied to all the resistivity profiles. The results 
obtained for both temperature correction methods (Hayley et al., 2007; Keller and Frischknecht, 1966) are virtually identical (Table 2).

Resistivity values from April to September generally increase subsequent to temperature correction. An increase of over $15 \%$ is observed in the top layer $(0.5 \mathrm{~m}$ depth $)$ from June to August, this increase gradually declines with depth and it can be considered negligible at depths over $5 \mathrm{~m}$. The opposite is observed for the cold months when a decrease of the resistivity values is observed after temperature correction from October to March. A maximum decrease of over $15 \%$ occurs for the months of January and December on the $0.5 \mathrm{~m}$ depth layer. Thus, resistivity values measured close to the surface show up to a $30 \%$ variation between the winter and summer records. Conversely, data collected during spring and autumn shows slight variations subsequent to temperature correction. The data presented in Table 2 emphasises that temperature correction should be taken into account for resistivity surveys in Ireland, particularly in shallow resistivity surveys investigating the top $5 \mathrm{~m}$ of the subsurface carried out during the winter and summer months.

\section{Conclusions}

Effective recharge, temperature, the depth of investigation, the sediment texture and the subsurface internal architecture are the main factors influencing the resistivity seasonal variation identified in this study. The electrode spacing used for data collection controls the spatial resolution of the inverse model of the pseudosection influencing the resistivity values and their seasonal variation.

Time-lapse analysis of ERT data showed an apparent relationship between electrical resistivity and groundwater effective recharge. The shallow subsurface ( $<4 \mathrm{~m}$ depth) showed a direct relationship between resistivity variation and effective recharge whereas, an increasing timelag between effective recharge and resistivity was recorded at increasing depths resulting in an inverse relationship. Areas in the vadose zone, at depths over 4-6 m, yield resistivity decreases during the drier season with null effective recharge, indicating that effective recharge encompasses an increasing time-lag with increasing depth. This allowed estimating the seepage velocity in unconsolidated relatively sorted unsaturated sediments recorded in the site (sand, gravelly sand and muddy sand). Seepage velocity could not be estimated for poorly sorted sediments (silt loam) showing little resistivity variation (Fig. 8a). The results draw attention to some of the limitations of the ERT method, which should be considered carefully during data interpretation: (i) resistivity variations depicted at the edges of the inverse model, poorly constrained by the data can be accentuated by artefacts produced during the inversion process; (ii) accuracy of seepage rate estimates are limited by the temporal resolution and the decrease of spatial resolution with depth, caused by the increasing size of the inversion model-blocks and the lower relative sensitivity in the deeper areas.

The relative position of the materials strongly influences their resistivity. Fine sediments in the shallow subsurface (Fig. 8a) encompass small resistivity variation $(<15 \%)$, however, sediments with silt/clay matrix (Fig. 1b) recorded in sample BhA-5 at $12 \mathrm{~m}$ depth show resistivity variation of over $80 \%$. Care has to be taken in the interpretation of time-lapse data in the deeper regions of the profile, as the recorded resistivity is highly influenced by the electrical properties of the overlying sediments and the spatial resolution decreases with depth (Loke, 2011). Furthermore, several materials located at depths over 4-6 $\mathrm{m}$ show their lowest resistivity values of the year during the summer months (Fig. $8 \mathrm{c}$ and d), this is interpreted as an effective recharge time-lag related to the velocity of the wetting front in these materials, however, a longer/higher resolution time recording period of at least two years is recommended to accurately interpret this unforeseen outcome. In addition, it is observed that the subsurface temperature strongly affects its resistivity. Resistivity values of the shallow subsurface, collected during the summer months, can be $30 \%$ higher than the same dataset collected in winter solely due to temperature variations. The installation of a weather station in site and the collection of temperature depth profiles would allow a more accurate temperature correction of the data. The results show that climate driven temperature changes have to be accounted for in the interpretation of ERT data and emphasise the potential of this technique for the estimation of the velocity of the wetting/drying fronts in unsaturated soft sediments.

\section{Acknowledgments}

The geophysical equipment used for this work was provided by the National University of Ireland, Maynooth Environmental Geophysics

Table 2

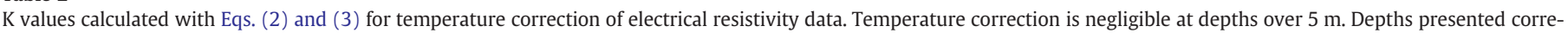
spond to the depth levels of the inverse model of the pseudosection of the profiles TL1 $-2 \mathrm{~m}$ and TL2 $-2 \mathrm{~m}$.

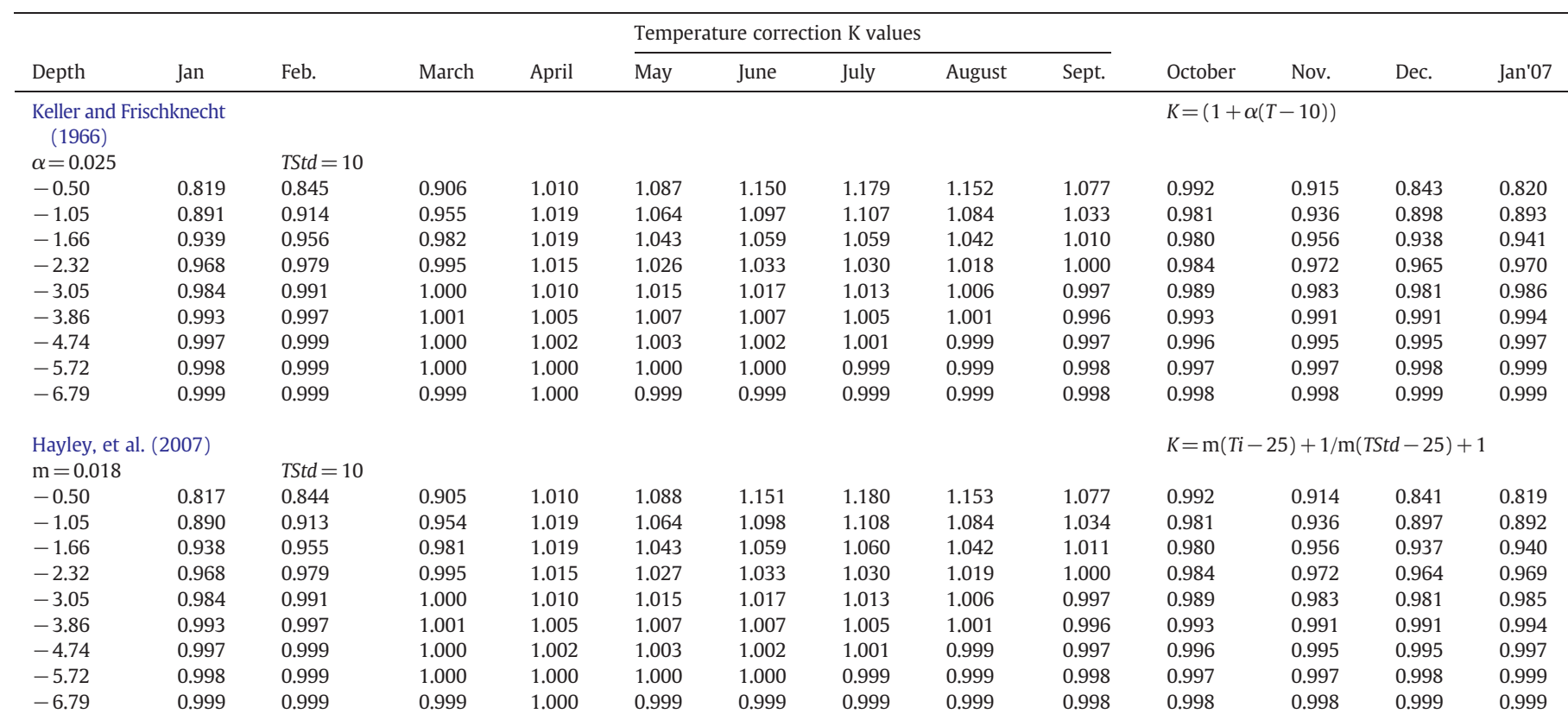


Unit. The Geological Survey of Ireland (GSI) funded the fieldwork and provided all the equipment for exposure recording, borehole drilling and particle size analysis. The authors would like to thank Caloca, S., Mozo, B. and Reves, M. for help in data collection and Cox, M. for facilitating access to the site. We also thank Dr. Jonathan Chambers for the constructive review comments, which highly improved the earlier version of the manuscript.

\section{References}

Allen, R.G., Pereira, L.S., Raes, D., Smith, M., 1998. Crop Evapotranspiration - Guidelines for Computing Crop Water Requirements - FAO IRRIGATION and Drainage Paper 56. FAO - Food and Agriculture Organization of the United Nations, Rome.

Allied Associates Ltd., 2006. Tigre Resistivity Meter User's Manual. Allied Associates Ltd., Dunstable, England.

Barker, R.D., Moore, J., 1998. The application of time-lapse electrical tomography in groundwater studies. Leading Edge 17 (10), 1454-1458.

Bear, J., 1972. Dynamics of Fluids in Porous Media. Dover Publications0-486-65675-6.

Bernstone, C., Dahlin, T., Ohlsson, T., Hogland, W., 2000. DC-resistivity mapping of internal landfill structures: two pre-excavation surveys. Environmental Geology 39 (3-4), 360-368.

Berthold, S., Bentley, L.R., Hayashi, M., 2004. Integrated hydrogeological and geophysical study of depression-focused groundwater recharge in the Canadian prairies. Water Resources Research 40, W06505. doi:10.1029/2003WR002982.

Brunet, P., Clément, R., Bouvier, C., 2010. Monitoring soil water content and deficit using Electrical Resistivity Tomography (ERT) - a case study in the Cevennes area, France. Journal of Hydrology 380, 146-153.

BS EN ISO 22476-2:2005, 2006. Geotechnical investigation and testing. Field Testing. Dynamic Probing. 0580476367.

Cassiani, G., Bruno, V., Villa, A., Fusi, N., Binley, A.M., 2006. A saline tracer test monitored via time-lapse surface electrical resistivity tomography. Journal of Applied Geophysics 59 (3), 244-259.

Chambers, J.E., Loke, M.H., Ogilvy, R.D., Meldrum, P.I., 2004. Noninvasive monitoring of DNAPL migration through a saturated porous medium using electrical impedance tomography. Journal of Contaminant Hydrology 68, 1-22.

Chambers, J.E., Meldrum, P.I., Gunn, D.A., Wilkinson, P.B., Kuras, O., Weller, A.L., 2009. Hydrogeophysical monitoring of landslide processes using Automated TimeLapse Electrical Resistivity Tomography (ALERT). Near Surface 2009 - 15th European Meeting of Environmental and Engineering Geophysics, Dublin, Ireland.

de Franco, R., Biella, G., Tosi, L., Teatini, P., Lozej, A., Chiozzotto, B., Giada, M., Rizzetto, F. Claude, C., Mayer, A., Bassan, V., Gasparetto-Stori, G., 2009. Monitoring the saltwater intrusion by time lapse electrical resistivity tomography: the Chioggia test site (Venice Lagoon, Italy). Journal of Applied Geophysics 69, 117-130.

Gibson, P.J., 2003. Seasonal effects on two dimensional time-lapse subsurface resistivity imaging. Proceedings of the Geophysical Association of Ireland/Irish Association of Hydrogeologists Conference 28/5/03 'Geophysical Applications in Hydrogeological Investigations', pp. 1-4.

Gibson, P.., 2005. Proceedings of the International Association of Hydrologists meeting: "Groundwater in Ireland", Tullamore 19-20th April. Advances in Geophysics - Timelapse Resistivity Imaging - Location and Movement of Landfill Plumes, pp. 117-121.

Goodman, R., Jones, G.L., Kelly, J., Slowey, E., O' Neill, N., 2004. Geothermal resource map of Ireland. Report Prepared by CSA for Sustainable Energy Ireland, Appendix VII, Map 6A.

Guerin, R., Muñoz, M.L., Christophe, A., Laperrelle, C., Hidra, M., Drouart, E., Grellier, S. 2004. Leachate recirculation: moisture content assessment by means of a geophysical technique. Waste Management 24, 785-794.

Harmon, E.J., Hajicek, M.F., 1992. Schlumberger soundings and sand-column resistivity testing for determining stream-aquifer connection of the Great Sand Dunes Natl. Monument, Colorado. Proceedings of the Symposium on the Application of Geophysics to Engineering and Environmental Problems, EEGS.

Hauck, C., 2002. Frozen ground monitoring using DC resistivity tomography. Geophysical Research Letters 29 (21), 2016-2019.

Hayashi, M., van der Kamp, G., Schmidt, R., 2003. Focused infiltration of snowmelt water in partially frozen soil under small depressions. Journal of Hydrology 270, 214-229.
Hayley, K., Bentley, L.R., Gharibi, M., Nightingale, M., 2007. Low temperature dependence of electrical resistivity: implications for near surface geophysical monitoring. Geophysical Research Letters 34, L18402.

Hayley, K., Bentley, L.R., Gharibi, M., 2009. Time-lapse electrical resistivity monitoring of salt-affected soil and groundwater. Water Resources Research 45, W07425.

Huntley, D., 1987. Relations between permeability and electrical resistivity in granular aquifers. Groundwater 24 (4), 466-474.

Johansson, S., Dahlin, T., 1996. Seepage monitoring in an earth embankment dam by repeated resistivity measurements. European Journal of Environmental and Engineering Geophysics 1, 229-247.

Keller, G.V., Frischknecht, F.C., 1966. Electrical Methods in Geophysical Prospecting. Pergamon Press.

Kneisel, C., 2006. Assessment of subsurface lithology in mountain environments using 2D resistivity imaging. Geomorphology 80, 32-44.

Leroux, V., Dahlin, T., 2006. Time-lapse resistivity investigations for imaging saltwater transport in glaciofluvial deposits. Environmental Geology 49, 347-358.

Loke, M.H., 2001. Electrical imaging surveys for environmental and engineering studies, a practical guide to 2-D and 3-D surveys: RES2DINV Manual, IRIS Instruments. www. iris-instruments.com2001.

Loke, M.H., 2011. Electrical Imaging Surveys for Environmental and Engineering Studies - A Practical Guide to 2D and 3D Surveys. Penang, Malaysia.

Loke, M.H., Barker, R.D., 1996. Rapid least squares inversion of apparent Resistivity pseudosections by a quasi-Newton method. Geophysical Prospecting 44, 131-152.

Miller, C.R., Routh, P.S., Brosten, T.R., McNamara, J.P., 2008. Application of time-lapse ERT imaging to watershed characterization. Geophysics 73 (3), G7-G17.

Monego, M., Cassiani, G., Deiana, R., Putti, M., Passadore, G., Altissimo, L., 2010. A trace test in a shallow heterogeneous aquifer monitored via time-lapse surface electrical resistivity tomography. Geophysics 75 (4), 61-73.

Morard, S., Delaloye, R., Lambiel, C., 2008. Time-lapse Electrical Resistivity Tomography (ERT) to estimate temperature changes at depth in a low elevation ventilated cold talus slope (Dreveneuse, Swiss Prealps). Geophysical Research Abstracts 10 EGU2008-A-09521.

Musy, A., Soutter, M., 1991. Physique du sol. Presses Polytechniques et Universitaires Romandes, Lausanne. Collection gérer l'environnement, 348 p.

Ogilvy, R.D., Kuras, O., Meldrum, P.I., Wilkinson, P.B., Chambers, J.E., Sen, M., Tsourlos, P. 2009. Monitoring saline intrusion of a coastal aquifer with automated electrical resistivity tomography. Near Surface 2009 - 15th European Meeting of Environmental and Engineering Geophysics, Dublin, Ireland.

Oldenborger, G.A., Knoll, M.D., Routh, P.S., LaBrecque, D.J., 2007. Time-lapse ERT monitoring of an injection/withdrawal experiment in a shallow unconfined aquifer. Geophysics 72 (4), 177-187.

Pellicer, X.M., Gibson, P., 2011. Electrical resistivity and ground penetrating radar for the characterisation of the internal architecture of Quaternary sediments in the Midlands of Ireland. Journal of Applied Geophysics 75, 638-647.

Radulescu, M., Valerian, C., Yang, J., 2007. Time-lapse electrical resistivity anomalies due to contaminant transport around landfills. Annals of Geophysics 50 (3) 453-468.

Revil, A., Cathles III, L.M., Losh, S., Nunn, J.A., 1998. Electrical conductivity in shaly sands with geophysical applications. Journal of Geophysical Research 103, 23,925-23,936.

Shevnin, V., Mousatov, A., Ryjov, A., Delgado-Rodriquez, O., 2006. Estimation of clay content in soil based on resistivity modeling and laboratory measurements. Geophysical Prospecting 55 (2), 265-275.

Sjödahl, P., Dahlin, T., Johansson, S., Loke, M.H., 2008. Resistivity monitoring for leakage and internal erosion detection at Hällby embankment dam. Journal of Applied Geophysics 65, 155-164.

Ward, A.S., Gooseff, M.N., Singha, K., 2010. Imaging hyporheic zone solute transport using electrical resistivity. Hydrological Processes 24, 948-953.

Yaramanci, U., 2000. Geoelectric exploration and monitoring in rock salt for the safety assessment of underground waste disposal sites. Journal of Applied Geophysics 44 181-196.

Zarroca, M., Bach, J., Linares, R., Pellicer, X.M., 2011. Electrical methods (VES and ERT) for identifying, mapping and monitoring different saline domains in a coastal plain region (Alt Empordà, Northern Spain). Journal of Hydrology 28, 407-422. 